\title{
Schwann Cell Proliferation and Migration During Paranodal Demyelination
}

\author{
John W. Griffin,, ${ }^{1,2}$ Nancy Drucker, ${ }^{1}$ Bruce G. Gold, ${ }^{3, a}$ Jeffrey Rosenfeld, ${ }^{1}$ Max Benzaquen, ${ }^{1, b}$ Lawrence R. \\ Charnas, ${ }^{1}$ Kenneth E. Fahnestock, ${ }^{1}$ and E. Adelaine Stocks ${ }^{1}$

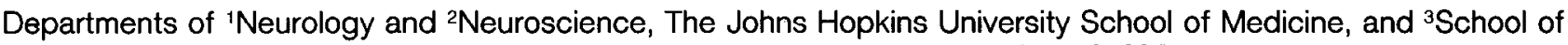 \\ Environmental Health Sciences, Johns Hopkins University, Baltimore, Maryland 21205
}

This study examined Schwann cell behavior during paranodal demyelination induced by $\beta, \beta^{\prime}$-iminodipropionitrile (IDPN). The stimuli for Schwann cell proliferation, extensively studied in vitro, are less well understood in vivo. Most in vivo systems previously used to examine Schwann cell proliferation in disease are dominated by loss of Internodal myelin sheaths. As used in this study, IDPN administration produces neurofilamentous axonal swellings and paranodal demyelination, without segmental demyelination or fiber degeneration. We asked whether Schwann cells would proliferate following the restricted paranodal demyelination that accompanies the axonal swellings, and if so what the sources and distributions of new Schwann cells might be.

IDPN was given as a single large dose $(2 \mathrm{ml} / \mathrm{kg})$ to $21-\mathrm{d}$ old rats. Neurofilamentous axonal swellings formed in the proximal regions of motor axons, reaching their greatest enlargement in the root exit zone $8 \mathrm{~d}$ after IDPN administration. These swellings subsequently migrated distally down the nerves at rates approaching $1 \mathrm{~mm} / \mathrm{d}$. The axonal enlargement was consistently associated with displacement of the myelin sheath attachment sites into internodal regions, and consequent paranodal demyelination. This stage was associated with perikaryal changes, including nucleolar enlargement, "girdling" of the perikaryon, and formation of attenuated stalks separating the perinuclear region from the external cytoplasmic collar.

Schwann cells proliferated abundantly during this stage. Daughter Schwann cells migrated within the endoneurial space (outside the nerve fiber basal laminae) to overlie the demyelinated paranodes of swollen nerve fibers. In these regions, local proliferation of Schwann cells continued, resulting in large paranodal clusters of Schwann cells. As the axonal calibers subsequently returned to normal, the outermost myelin lamellae of the original internodes returned to their paranodal attachment sites and the supernumerary Schwann cells disappeared. Formation of short internodes,

Received Mar. 13, 1986; revised July 22, 1986; accepted Aug. 8, 1986.

This work was supported by NIH Grant NS22849 and the Vanderklute and Dunning funds for research on motor neurons. We thank Drs. Bruce Trapp, Cedric Raine, and Peter Spencer for helpful discussions.

Correspondence should be addressed to John W. Griffin, Department of Neurology, The Johns Hopkins University School of Medicine, 600 North Wolfe Street, Baltimore, MD 21205.

a Present address: Department of Pharmacology and Toxicology, Rutgers University School of Pharmacy, New Brunswick, NJ.

b Present address: Hospital Santa Toribio de Mogrovejo, Lima, Peru.

Copyright (c) 1987 Society for Neuroscience $0270-6474 / 87 / 030682-18 \$ 02.00 / 0$ segmental demyelination, and nerve fiber loss were rare phenomena. These results indicate that paranodal demyelination is a sufficient stimulus to excite abundant Schwann cell proliferation; neither internodal demyelination nor myelin breakdown is a necessary stimulus for mitosis.

The ${ }^{\text {अ }} \mathrm{H}$-thymidine incorporation studies indicated that the sources of new Schwann cells included markedly increased division of the Schwann cells of unmyelinated fibers and, as they formed, supernumerary Schwann cells. In addition, there were rare examples of ${ }^{3} \mathrm{H}$-thymidine incorporation by Schwann cells associated with myelinated nerve fibers. These labeled Schwann cells were located within the basal lamina of the internodal nerve fiber. Whether these dividing Schwann cells were maintaining myelin sheaths is unresolved; in no fiber could the outer Schwann cell plasmalemma of a labeled cell be traced into the outer mesaxon of the myelin sheath. The daughter Schwann cells from these various sources migrated to sites of paranodal demyelination. Taken together, the proliferation of multiple Schwann cell populations and eventual localization of Schwann cells over demyelinated regions suggest that diffusible mitogenic and chemotropic factors may be elaborated during paranodal demyelination.

The responses of Schwann cells to internodal (segmental) demyelination have been examined in increasing detail for more than 100 years (Gombault, 1880). In contrast, few studies have addressed the behavior of Schwann cells during demyelination restricted to the paranodal regions. The giant axonal neuropathies provide useful model systems in which to examine paranodal demyelination. These neuropathies, whether heritable or induced by chemical neurotoxins, are characterized by focal or multifocal accumulations of neurofilaments; the resulting axonal swellings produce displacement of the myelin terminal loops from their paranodal attachment sites into the internodes of affected fibers, resulting in paranodal demyelination (Asbury et al., 1972; Spencer and Schaumburg, 1977; Griffin and Price, $1981 \mathrm{a}$; Jones and Cavanagh, 1983a). Late changes seen in the neurofilamentous neuropathies, including segmental demyelination with remyelination and onion bulb formation (Shimono et al., 1978; Griffin and Price, 1981a), are rarely seen in the first few weeks after initiation of axonal enlargement. Giant axonal neuropathies thus offer models in which demyelination is not accompanied by loss of the myelin sheath over the central region of the internode or by evidence of myelin breakdown.

In this report we describe the early responses of Schwann cells 

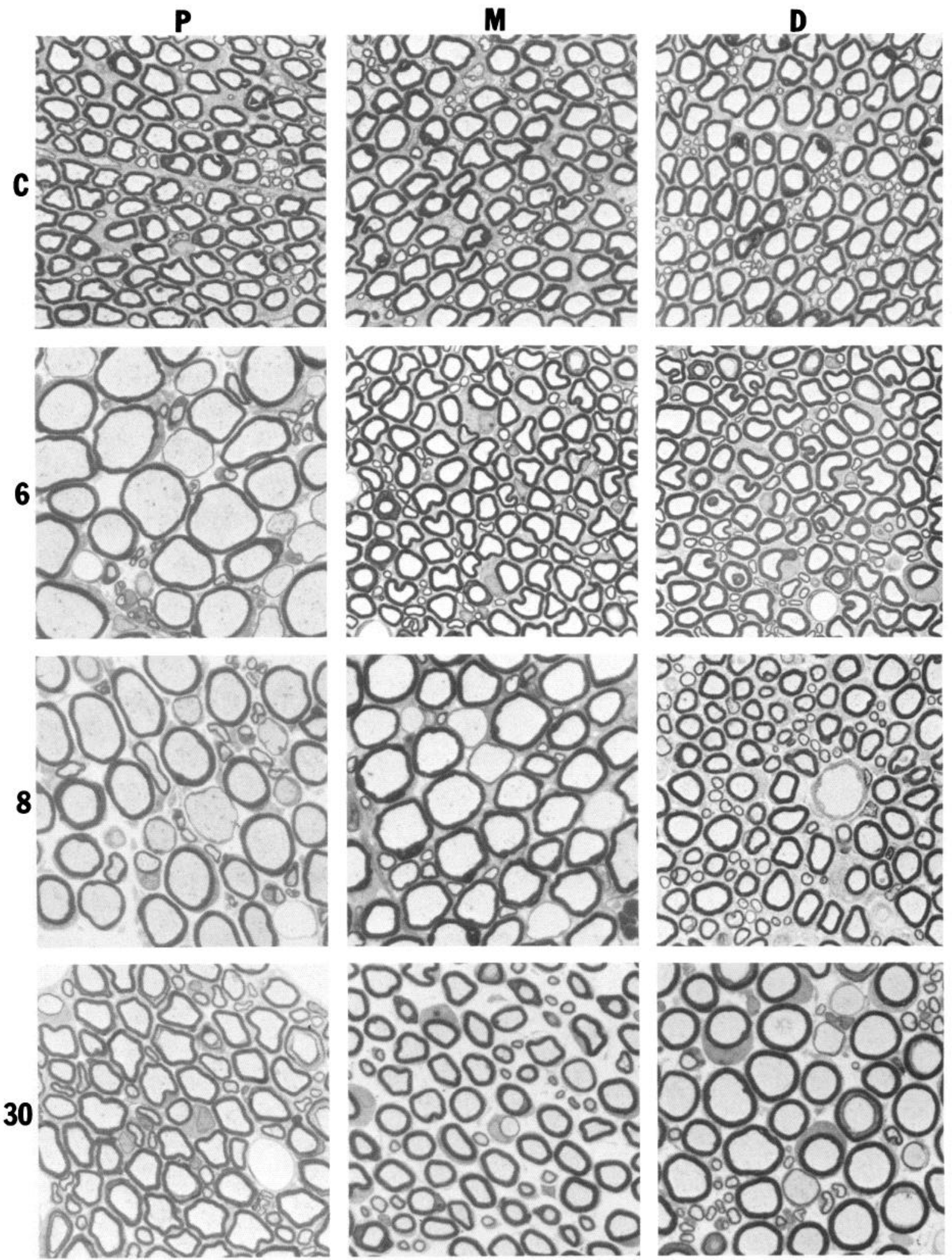

Figure 1. Light micrographs of cross sections of the L5 ventral root of control and IDPN-treated rats. For each root the most proximal 3 mm segment $(P)$ is to the left; the middle region $(M)$ is in the center, and the distalmost segment $(D)$ is to the right. $C=\mathrm{C} 21$, a 21-d-old control animal; $6=\mathrm{I} 6(27)$, a $27-\mathrm{d}$-old animal $6 \mathrm{~d}$ after IDPN administration; $8=\mathrm{I} 8(29) \mathrm{d} ; 30=\mathrm{I} 30(51) \mathrm{d}$. Note that by $6 \mathrm{~d}$ axonal swellings are present at the most proximal region of the ventral root in the IDPN-treated animals but are not in the middle or distal region. By $8 \mathrm{~d}$ small swellings are beginning to appear at the middle region of the ventral root. By $30 \mathrm{~d}$ swellings are most prominent in the distal region of the ventral root, and more proximal regions have undergone reduction in caliber. Note also that myelin sheath thickness around most fibers remains essentially unchanged throughout the changes in axonal caliber; a small proportion of fibers shows thin or absent myelin sheaths, reflecting sections through the paranodes. All sections $\times 680$. 


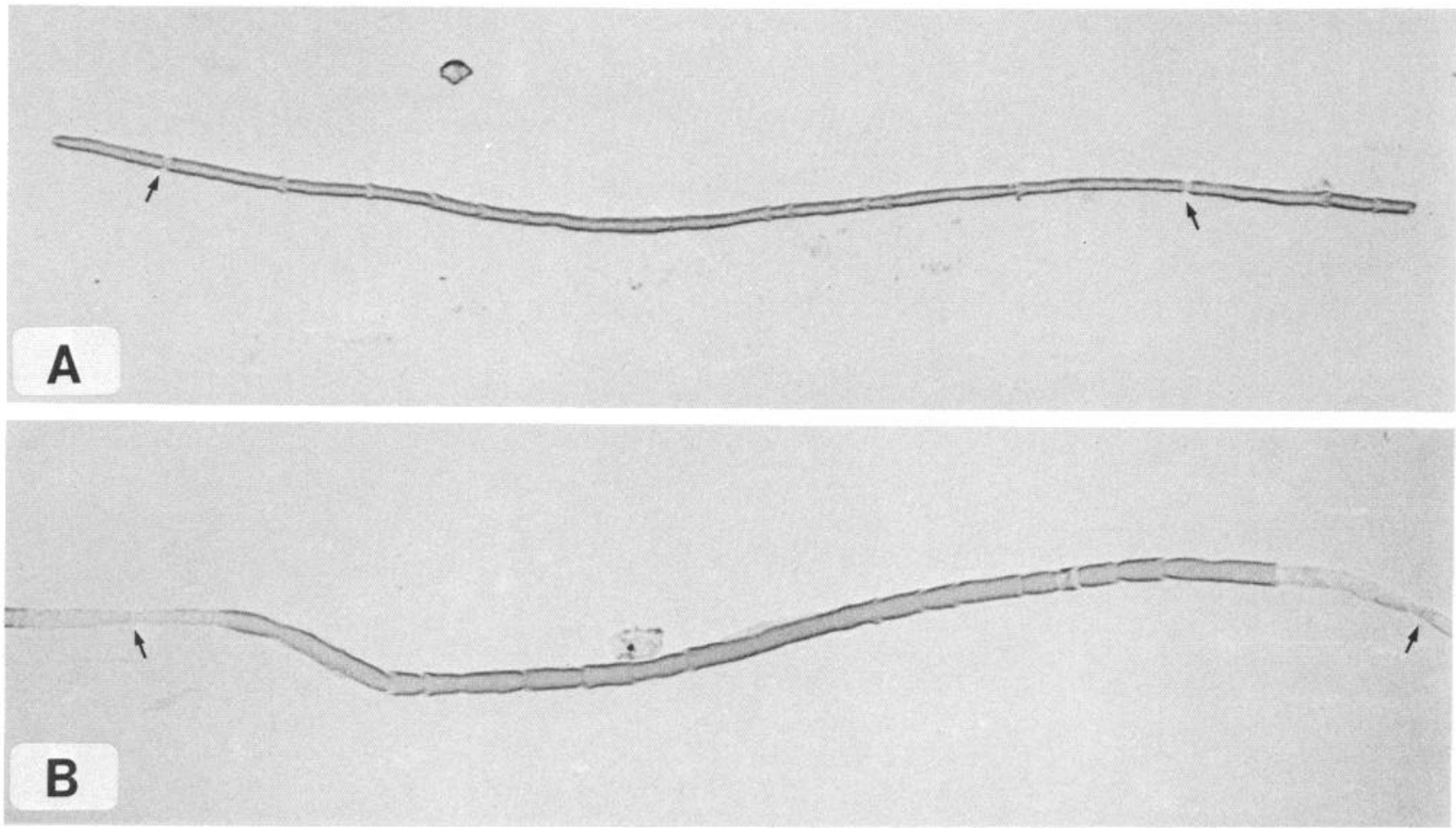

Figure 2. Teased fibers from the middle ventral root of a $\mathrm{C}(35)$ rat $(A)$ and an $\mathrm{I} 14(35)$ experimental animal $(B)$. Note the paranodal demyelination in $B$. Nodes are indicated by arrows in both $A$ and $B . \times 180$.

to rapid axonal enlargement and paranodal demyelination produced by $\beta, \beta^{\prime}$-iminodipropionitrile (IDPN). The changes described in this report include perikaryal alterations, with "girdling" and formation of perinuclear stalks, proliferation of Schwann cells, and migration of daughter Schwann cells along nerve fibers to form clusters around the demyelinated paranodes. The morphometric changes in the internodal myelin sheath will be described in a separate report.

\section{Materials and Methods}

\section{Tissue preparation}

Groups of 21-d-old male Sprague-Dawley rats (Harlan) received intraperitoneal injections of IDPN (Eastman, Rochester, NY; $2 \mathrm{ml} / \mathrm{kg}$ diluted 1:5 with saline). Groups of IDPN-treated animals were heparinized, anesthetized with chloral hydrate, and perfused through the ascending aorta with glutaraldehyde $(5 \%)$ in $0.1 \mathrm{~m}$ sodium phosphate buffer $(\mathrm{pH}$ 7.3). Groups of 3-5 animals were killed $2,4,6,8,10,14,30$, and 60 d after IDPN administration. Age-matched control groups were prepared for each experimental group. In each animal the L5 ventral and dorsal roots were dissected from the spinal cord to the mixed nerve just distal to the dorsal root ganglion. Each root was divided into 6-9 sequential $3 \mathrm{~mm}$ segments, and these samples were used to prepare both transverse and longitudinal sections. All specimens were postfixed with $2 \%$ osmium tetroxide in $0.1 \mathrm{M}$ phosphate buffer for $2 \mathrm{hr}$, dehydrated in graded alcohols, and embedded in Epon-Araldite resin. Sections, $1 \mu \mathrm{m}$, were stained with toluidine blue for light microscopy; thin sections were stained with uranyl acetate and lead citrate and examined in a Hitachi H-600 EM.

For fiber teasing, the root segments underwent osmication and were then placed in graded concentrations of glycerol and teased with sharpened insect pins in $100 \%$ glycerol. To examine the adhesion of supernumerary Schwann cells to nerve fibers, some nerves were removed without fixation and teased in a saline solution.

To simplify description of the spatial and temporal evolution of the changes in these roots, the preparations studied were designated as follows. Control groups of animals were identified by C, followed by the age in days on which the animals were killed, followed by the level of the root being described (proximal $3 \mathrm{~mm}$, middle $3 \mathrm{~mm}$, or distal 3 $\mathrm{mm}$ ) as $\mathrm{P}, \mathbf{M}$, or $\mathrm{D}$, respectively. For example, the proximal segment of the root of a 1-month-old control animal would be designated C30P. Experimental animals were designated by I, followed by the days after IDPN administration on which they were killed, the total age in days in parentheses, and then the level of the root, as described for control animals. Thus, the distal ventral root from an animal killed $14 \mathrm{~d}$ after IDPN administration would be designated I14(35)D. The same system of description was applied to both the dorsal and ventral roots; in the dorsal roots the proximal segment (the segment nearest the cord) is farthest from the nerve cell bodies in the dorsal root ganglion (DRG).

\section{${ }^{3} \mathrm{H}$-thymidine incorporation}

Autoradiographic studies. Rats were injected with ${ }^{3} \mathrm{H}$-thymidine (methyl- ${ }^{3} \mathrm{H}$-thymidine, $60 \mathrm{Ci} / \mathrm{mmol}$, ICN; $6 \mu \mathrm{Ci} / \mathrm{gm}$ total dose) in 4 divided doses over $24 \mathrm{hr}$. One hour after the last injection they were killed by perfusion with the fixative solution described above. The proximal, middle, and distal segments of the L5 ventral root were sectioned transversely, dipped in Kodak NTB4 emulsion, exposed for $30 \mathrm{~d}$, and developed in Kodak D19 developer. For comparison with ventral roots, L5 dorsal roots at the same levels were similarly prepared in control and 8-d-old animals. The number of total labeled cells in the endoneurial space (inside the root sheath), excluding cells associated with blood vessels, was counted, as was the total number of "free" cells (unassociated with nerve fibers); as indicated below, in the experimental groups most of these cells were supernumerary Schwann cells. The changes in the temporal and spatial distribution of labeled cells and supernumerary cells were compared to the change in axonal caliber for each level of the root.

To characterize precisely the cells incorporating ${ }^{3} \mathrm{H}$-thymidine, EM autoradiograms were prepared as previously described (Griffin et al., 1981).

In vitro studies of thymidine incorporation. I7(28) and I14(35) animals and groups of age-matched control animals were anesthetized with chloral hydrate, and the L5 dorsal roots with the attached sciatic nerves were rapidly dissected. These preparations were transferred to flasks containing $40 \mathrm{ml}$ HEPES-buffered Ringer's solution with glucose and $10 \mu \mathrm{Ci} / \mathrm{ml}^{3} \mathrm{H}$-thymidine. The flasks were gently bubbled with $100 \% \mathrm{O}_{2}$ 


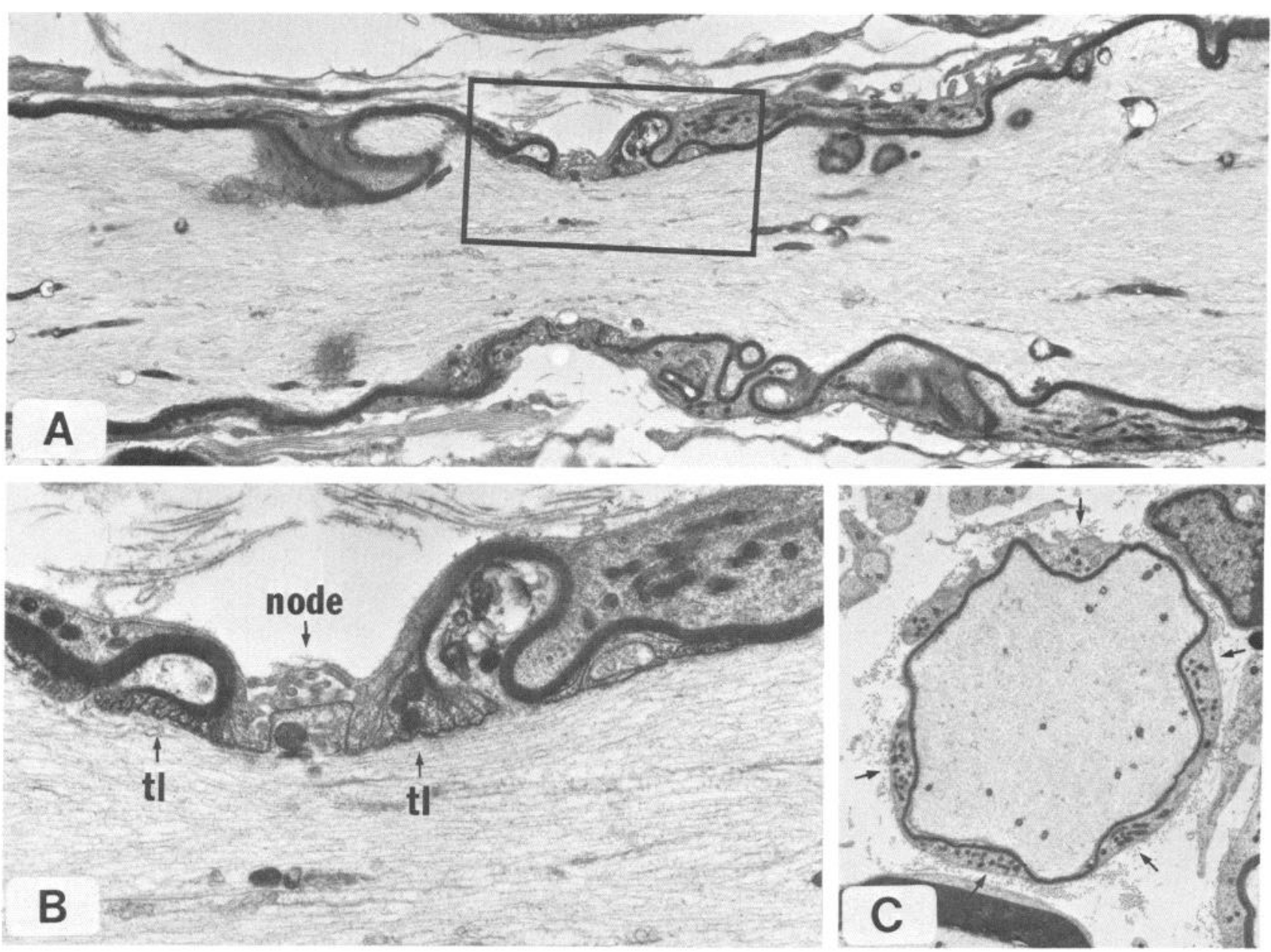

Figure 3. Longitudinal section through the proximal ventral root $30 \mathrm{~d}$ after administration of IDPN. In $A(\times 4900)$ note that the outermost myelin terminal loops have returned to their original (pre-intoxication) insertion sites. The nodal region (boxed) is seen at higher power in $B(\times 14,700)$. Note the wrinkled serpentine appearance of the myelin. Because many myelin lamellae continue to terminate in (pre-intoxication) internodal regions, the entire region shown in $A$ has characteristics of paranodal organization $(t l=$ terminal loops). $C(\times 5000)$ illustrates the appearance of this elongated paranodal region in cross sections; the myelin sheath is relatively thin. The paranodal nature of these regions can be recognized by the "gutters" of mitochondria-rich Schwann cell cytoplasm (arrows).

during $3 \mathrm{hr}$ incubations at $37^{\circ} \mathrm{C}$. To determine the condition of the nerves at the end of the incubations, 2 of the experimental nerves were fixed and embedded as described above, and autoradiograms prepared. The nerve roots were well preserved and morphologically comparable to nerves fixed in situ. The label was predominantly associated with Schwann cell nuclei, as described below for in vivo labeling.

The rest of the in vitro preparations were divided into $3 \mathrm{~mm}$ segments that were washed with cold TCA for $1 \mathrm{hr}$ and refrigerated overnight in a second wash. The nerve segments were dissolved in $0.8 \mathrm{ml} 2 \mathrm{~N} \mathrm{NaOH}$ at $60^{\circ} \mathrm{C}$. The solutions were made acidic with $1 \mathrm{ml} \mathrm{HCl}$ and counted in Ultrafluor in a Beckman LS 150 liquid scintillation spectrometer.

\section{Results}

\section{Spatial and temporal distribution of the axonal swellings}

In control animals the numbers of fibers were nearly identical at all root levels, and the fiber calibers showed less than $10 \%$ tapering in the proximal to distal direction (Hoffman et al., 1984, 1985) (Fig. 1C).

IDPN administration on day 21 resulted in a highly consistent sequence of axonal changes. Axonal enlargement appeared at the proximal level of the ventral root between days 2 and 3 , and by days 4-6 (Fig. 1, 6 d) sizable swellings were present. The greatest degree of enlargement in the proximal region was reached by day 8 (Fig. 1, 8 d). At this stage, there was a slight degree of atrophy in the distal ventral root segments (at the level of the DRG). By day 14, axonal calibers were decreasing proximally as the swellings appeared in the midroot region. This redistribution of the swellings reflected proximal-to-distal migration of the neurofilamentous masses, similar to that seen in other neurofilamentous neuropathies (Cavanagh, 1982). With time, the swellings became less sharply localized, and some enlarged fibers could be found at all levels of the ventral root by $30 \mathrm{~d}$ (Fig. 1, $30 \mathrm{~d}$ PMD). At this time, the peak of the swellings was $27 \mathrm{~mm}$ from the root exit zone. Thus, the region of largest swellings migrated $24 \mathrm{~mm}$ (from the proximal to the distal segment of the ventral root) between days 6 and 30, reflecting a rate of movement of about $1 \mathrm{~mm} / \mathrm{d}$.

Comparable changes were seen in the dorsal root; the swellings formed initially near the cell bodies in the intraganglionic portion of the distal dorsal root and migrated toward the spinal cord with time.

\section{Paranodal demyelination}

Teased fiber studies and longitudinal sections showed that the rapidly developing swellings were fusiform with node, paranode, and internode all enlarged (Fig. 2). Pari passu with the axonal 


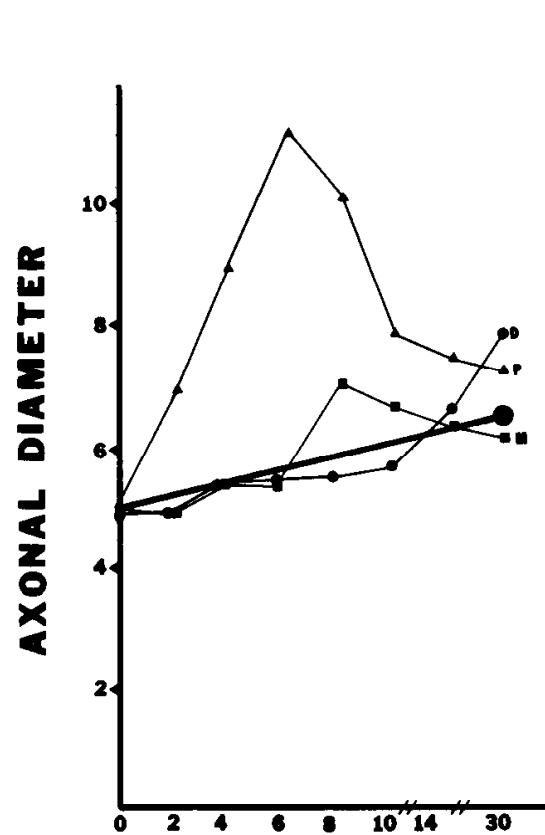

A DAYS POST IDPN

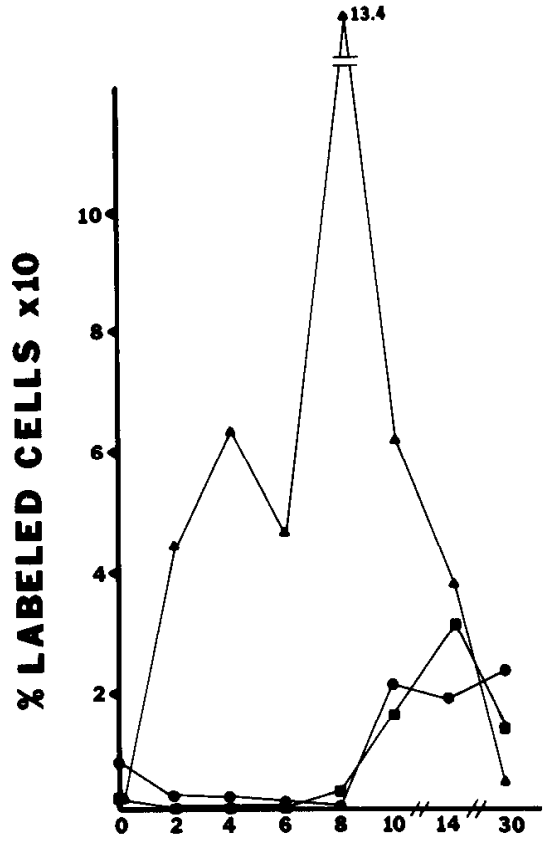

DAYS POST IDPN

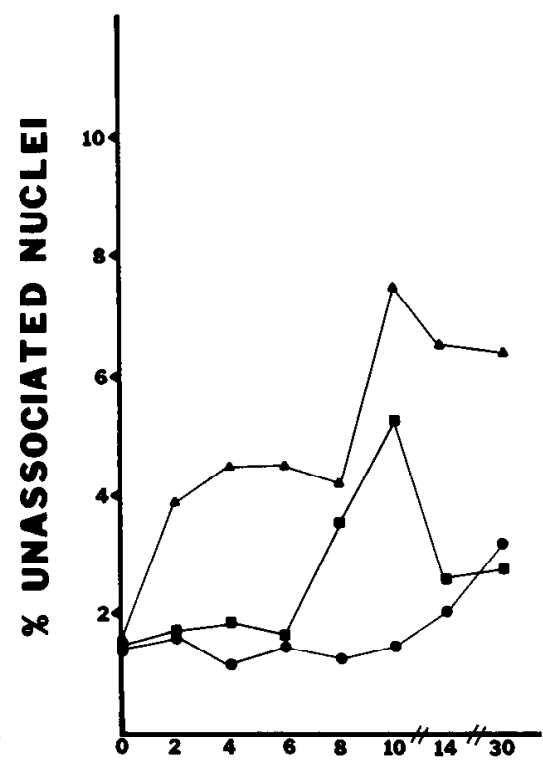

DAYS POST IDPN

Figure 4. Changes in axonal diameter $(A)$, percentage of cells labeled by ${ }^{3} \mathrm{H}$-thymidine $(B)$, and number of supernumerary cell nuclei $(C)$ in the L5 ventral root of rats exposed to IDPN. In each graph the triangles represent the proximal $3 \mathrm{~mm}$ of the ventral root, the squares, the middle portion, and the circles, the most distal $3 \mathrm{~mm}$. Each of the points represents the mean from 3 animals. IDPN was given on postnatal day 21 . The axonal diameters in $A$ are mean values for the large fiber peak of histograms (at day 0 these are fibers $>3.25 \mu \mathrm{m}$ in diameter). The heavy solid line in $A$ represents the change in mean axonal diameter of the large fiber peak in untreated control animals; the increase represents age-related radial growth (Hoffman et al., 1984). In $B$ and $C$, control values remain at the levels indicated at day 0 . Note in $A$ that axonal diameters begin increasing by day 2 after IDPN administration and peak at day 6 in the proximal root; in the middle root less dramatic swellings are present at days 8-10, and in the distal root the swellings are largest at day 30 . Note in $B$ the dramatic increase in ${ }^{3} \mathrm{H}$-thymidine incorporation in the proximal root, with a peak at day 8 and a return toward control values between days 8 and 30 . Labeling increases in the middle and distal roots at later times. In $C$ note that the proportion of nuclei not associated with nerve fibers increases in the first $10 \mathrm{~d}$ after IDPN administration in the proximal root and in the middle root region but reaches its maximum increase at day 30 in the distal ventral root. In control animals $(0 \mathrm{~d})$ these unassociated nuclei are predominately nuclei of endoneurial fibroblasts; in the experimental nerves the increase in unassociated nuclei reflects the appearance of supernumerary Schwann cells in the endoneurium.

swclling, myelin terminal loops were displaced from their usual insertion sites in the paranode into the (pre-intoxication) internodal region, reproducing a form of paranodal demyelination common to a variety of disorders in which axonal swelling occurs (Friede and Martinez, 1970; Asbury et al., 1972; Spencer and Schaumburg, 1977; Griffin et al., 1981b; Jones and Cavanagh, 1983a; Stanley et al., 1985). The inner lamellae were displaced further than the outer lamellae, so that the sheath
Figure 5. Change in the distribution of ${ }^{3} \mathrm{H}$-thymidine incorporation along the L5 dorsal root after IDPN intoxication. Each point is the mean of 3-5 measurements. $=$ control root; $O=7 \mathrm{~d}$ after IDPN; $=14 \mathrm{~d}$ after IDPN. The first segment $(0-3 \mathrm{~mm})$ is the dorsal root ganglion in all preparations. Note that this segment has the highest level of incorporation in normal animals; there is a flat plateau of incorporation in the remaining segments. Seven days after IDPN, thymidine incorporation is stimulated in the segments adjacent to the ganglion, and by $14 \mathrm{~d}$ the peak is in the middle portion of the root. This changing pattern reflects the changing distribution of axonal swelling and paranodal demyelination.

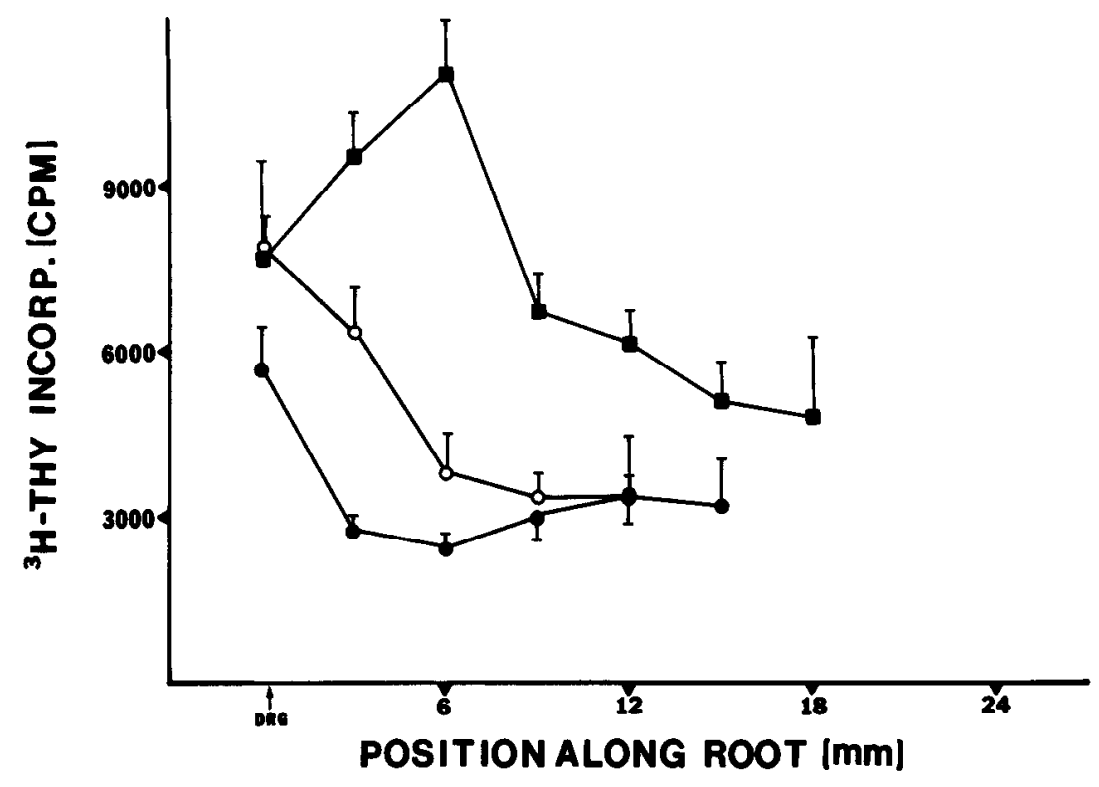



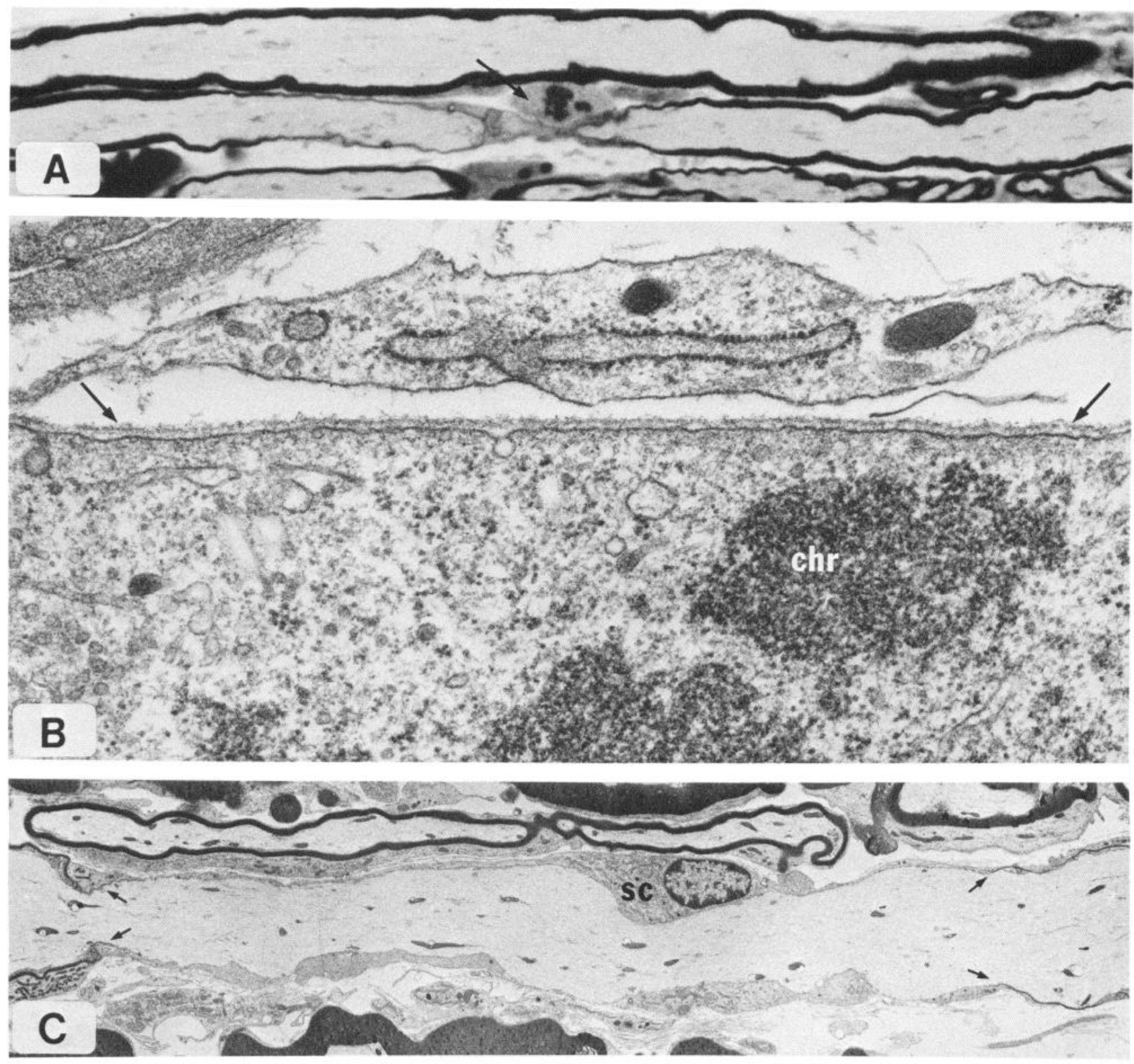

Figure 6. Schwann cell mitosis and axonal ensheathment near demyelinated paranodes in the ventral root of IDPN-treated rats. $A$, Longitudinal section showing a mitotic figure (arrow) in a supernumerary Schwann cell adjacent to a region of paranodal demyelination in an I6(27) rat. $\times 1100$. $B$, Electron micrograph demonstrating the intact basal lamina (arrows) surrounding a metaphase Schwann cell $($ chr $=$ chromosome). $\times 40,000$. $C$, Ensheathment of a demyelinated nodal-paranodal region by a daughter Schwann cell $(s c)$ in an I14(35) ventral root. The outermost lamallae of the original internodes are designated by arrows. $\times 2470$.

thinned progressively between the internode and the demyelinated region. The IDPN model is unusual in that the Schwann cell cytoplasm and microvilli were often displaced from the paranodes as well, so that the nodal and paranodal axolemma was separated from the endoneurial space only by Schwann cell basal lamina (Stanley et al., 1985).

As the swellings migrated centrifugally and the axonal caliber returned toward normal, the outermost terminal loops returned to their original insertion sites. The myelin at this stage was characteristically wrinkled by redundant folds and knuckles, seen in both longitudinal and cross sections. Because many myelin terminal loops continued to terminate in the (pre-intoxication) internode, the paranodal myelin remained thin. In cross sections a characteristic paranodal appearance, including "gutters" of mitochondria-rich Schwann cell cytoplasm, extended for up to $50 \mu \mathrm{m}$ from the node (Fig. 3).

\section{Schwann cell proliferation}

Schwann cell proliferation was closely associated with the axonal swellings, both in space and time (Figs. 4,5 ). In the ventral roots of $\mathrm{C} 21$ and $\mathrm{C} 49$ control animals (3-7 weeks of age), the labeling index was very low $(0.03 \%)$. In the proximal ventral root, increased incorporation was present by $2 \mathrm{~d}$ after IDPN administration, as the earliest swellings appeared in the region. The fraction of labeled cells increased to a level 40 -fold greater than controls by $8 \mathrm{~d}$ (Fig. 4). Between 8 and $30 \mathrm{~d},{ }^{3} \mathrm{H}$-thymidine incorporation decreased proximally but increased in the more distal segments (as the swellings invaded these regions). The in 

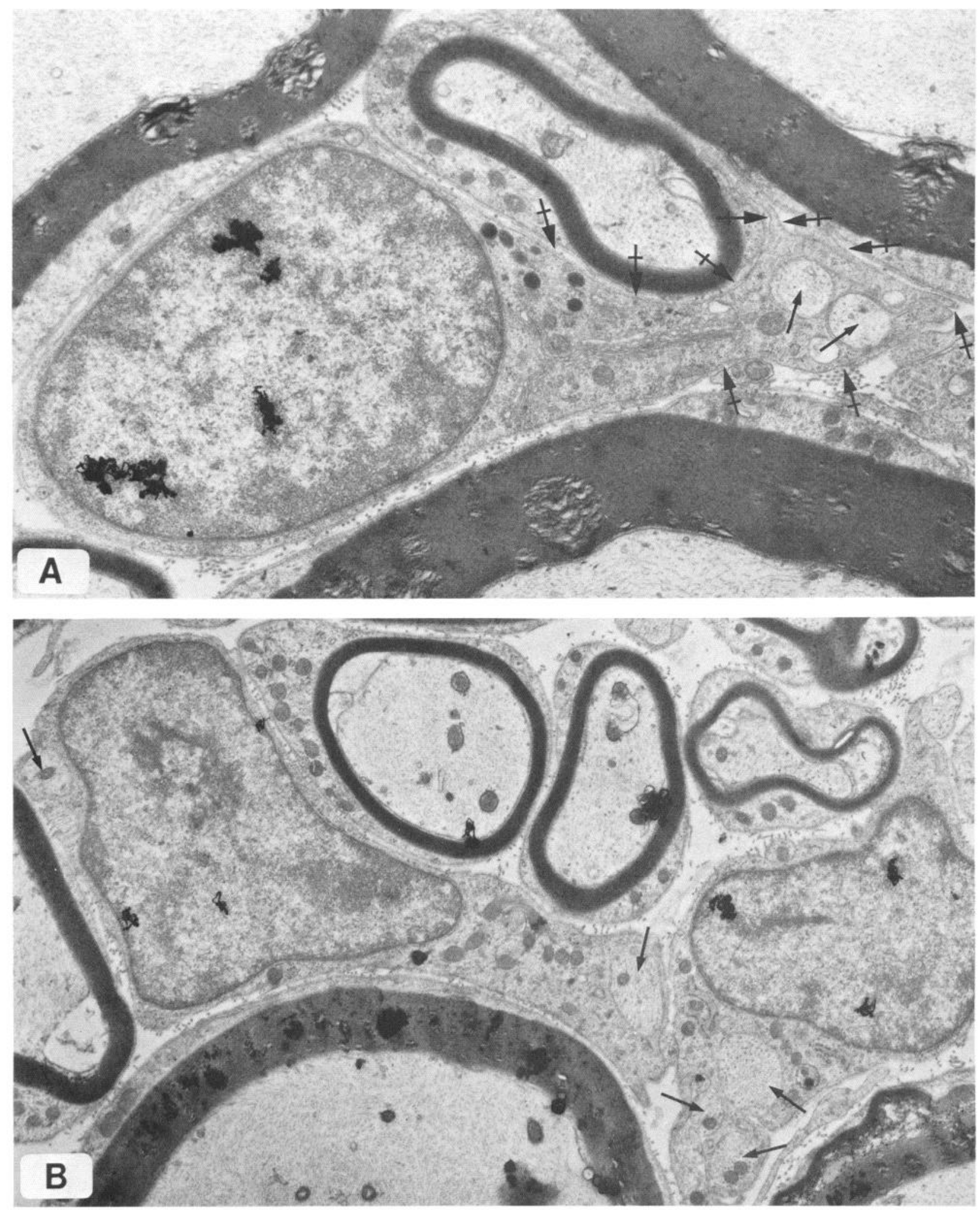

Figure 7. EM autoradiograms demonstrating incorporation of tritiated thymidine into the Schwann cell nuclei in unmyelinated nerve fibers of an I6(27) rat. Thymidine was given in 4 divided doses over $24 \mathrm{hr}$ before fixation of the nerves. A, Two unmyelinated axons (arrows) are seen within the stalklike process of this Schwann cell (outlined by barred arrows); basal lamina surrounds the perikaryal region as well as most of the stalklike process. $\times 15,700 . B$, Labeled nuclei in neighboring unmyelinated fiber bundles. Note that the axons (examples identified by arrows) have densely packed neurofilaments. $\times 11,200$. 

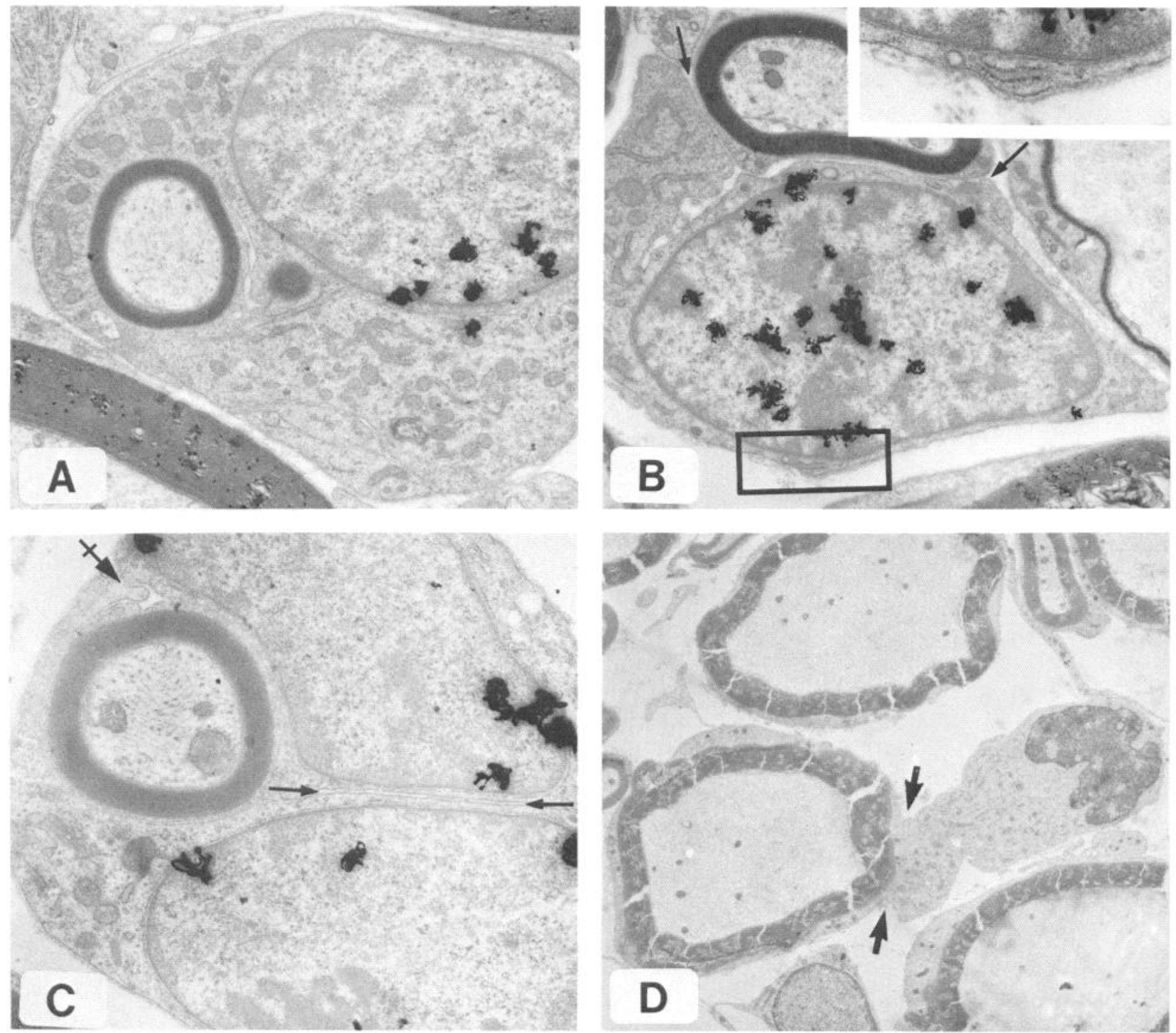

Figure 8. Electron micrographs showing incorporation of tritiated thymidine $(A-C)$ or mitotic figures $(D)$ in Schwann cells associated with myelinated nerve fibers. In the autoradiographic studies, ${ }^{3} \mathrm{H}$-thymidine was given to an I6(27) rat in 4 divided doses over $24 \mathrm{hr}$ before fixation of the nerves. $A$, This small myelinated fiber contains a labeled Schwann cell nucleus. Whether this labeled Schwann cell is maintaining the myelin sheath is uncertain; it is not possible to trace the plasmalemma of the labeled Schwann cell into the myelin sheath. $\times 11,000$. B, Labeled Schwann cell associated with a small myelinated nerve fiber. Note that the apposed Schwann cell processes are separated by a $16 \mathrm{~nm}$ space (arrows) without intervening basal lamina. $\times 10,000$. A partial basal lamina surrounds the labeled Schwann cell (boxed region, seen at a higher power in the inset). $\times 23,000$. $C$, Two labeled Schwann cell nuclei associated with a small myelinated fiber. Note that the nerve fiber is surrounded by basal lamina, but the apposed surfaces of these 2 Schwann cells do not contain basal lamina and are separated by a $16 \mathrm{~nm}$ gap (arrows). Whether either of these Schwann cells is maintaining this myelin sheath is uncertain. Barred arrow identifies overlapping Schwann cell processes near the outer mesaxon. $\times 17,000$. D, Electron micrograph of a prophase Schwann cell nucleus associated through a stalklike projection with a large myelinated fiber. (The myelin artifacts are changes sustained during reembedding and sectioning of the $1 \mu \mathrm{m}$ section in which this fiber was identified.) Although at low power it appears there is continuity between the Schwann cell of the myelinated fiber and the mitotic cell, tilting demonstrated a persistent gap without intervening basal lamina in the region identified by arrows. $\times 3600$.

vitro studies showed a similar sequence in the dorsal root, with increased thymidine incorporation beginning near the cell bodies of the DRG (distal dorsal root) and appearing further from the ganglion (more proximal dorsal root) with time (Fig. 5).

In control roots, EM autoradiography showed that incorporation of ${ }^{3} \mathrm{H}$-thymidine by cells was restricted to a small proportion of unmyelinated nerve fibers. No free or supernumerary Schwann cells were identified in control nerves (supernumerary cells are here defined as Schwann cells that do not ensheath an axon and are found lying in the endoneurial space outside the basal lamina of neighboring nerve fibers).
The cells that were dividing in I8(29) proximal ventral roots included supernumerary Schwann cells, which were already present. Proliferation of supernumerary Schwann cells was demonstrated by EM autoradiography (not shown) and by ultrastructural identification of cells containing mitotic figures (Fig. $6, A, B$ ). At least $60 \%$ of the cells containing mitotic figures could be definitively identified as Schwann cells on the basis of a complete or partial basal lamina (Fig. $6 B$ ); in the others, no basal lamina was identified, but cytologic features suggested that most were Schwann cells.

In addition to the labeling of the nuclei of supernumerary 

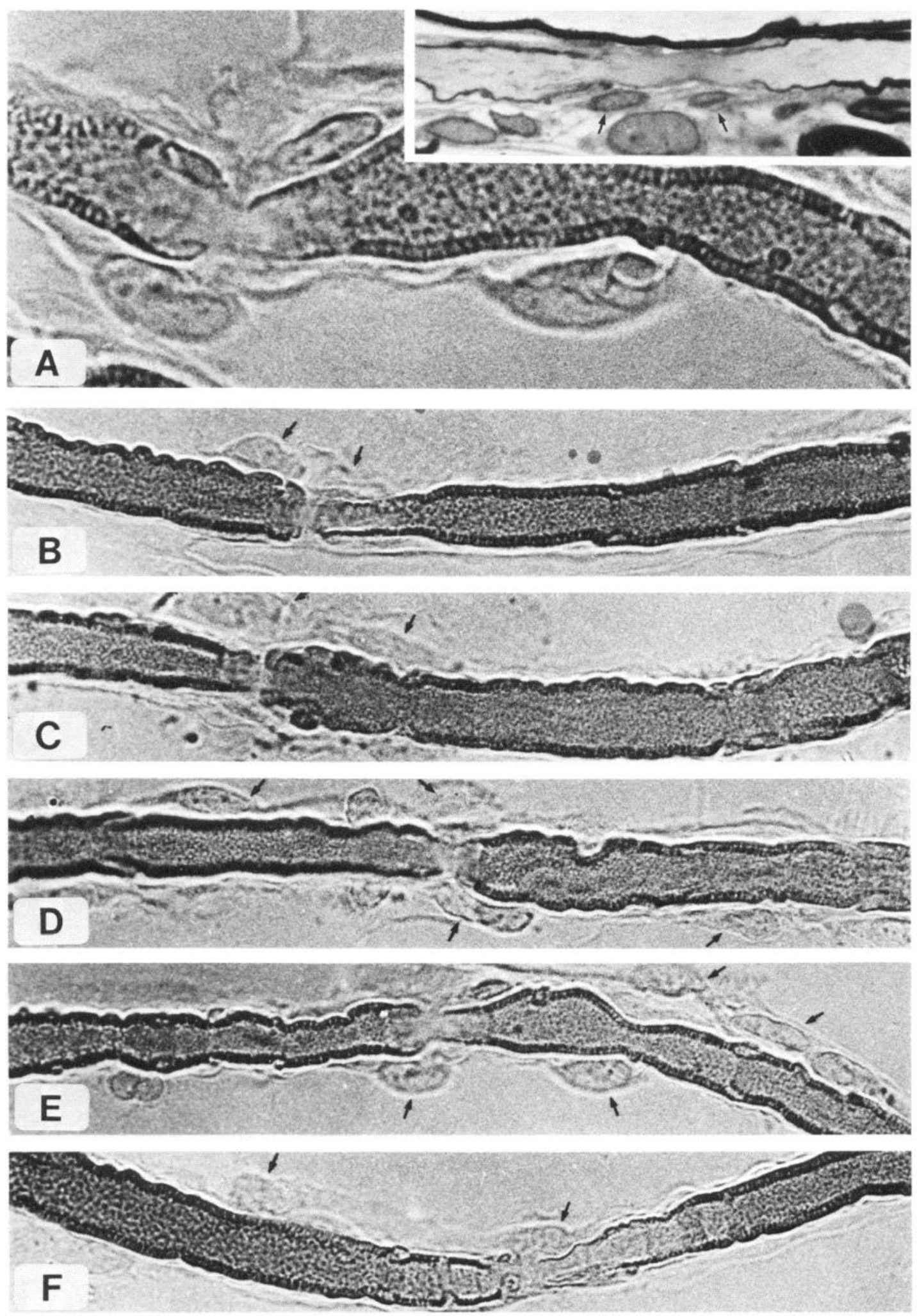

Figure 9. Teased nerve fibers illustrating paranodal Schwann swelling clusters. The top panel $(A)$ shows only mild paranodal displacement of myelin but free Schwann cells in the paranodal region $(\times 1850)$. The inset $(\times 1250)$ shows several supernumerary Schwann cells $(e x a m p l e s$ identified by arrows) near a demyelinated paranode $(1 \mu \mathrm{m}$ plastic section). The lower panels $(B-F$, all $\times 860)$ represent successive nodes of Ranvier from a single nerve fiber. Note that multiple Schwann cells are present around each of the paranodal regions; only rare supernumerary Schwann cells were found in the intervening internodal regions (not shown). Examples of paranodal Schwann cells are identified by arrows. 

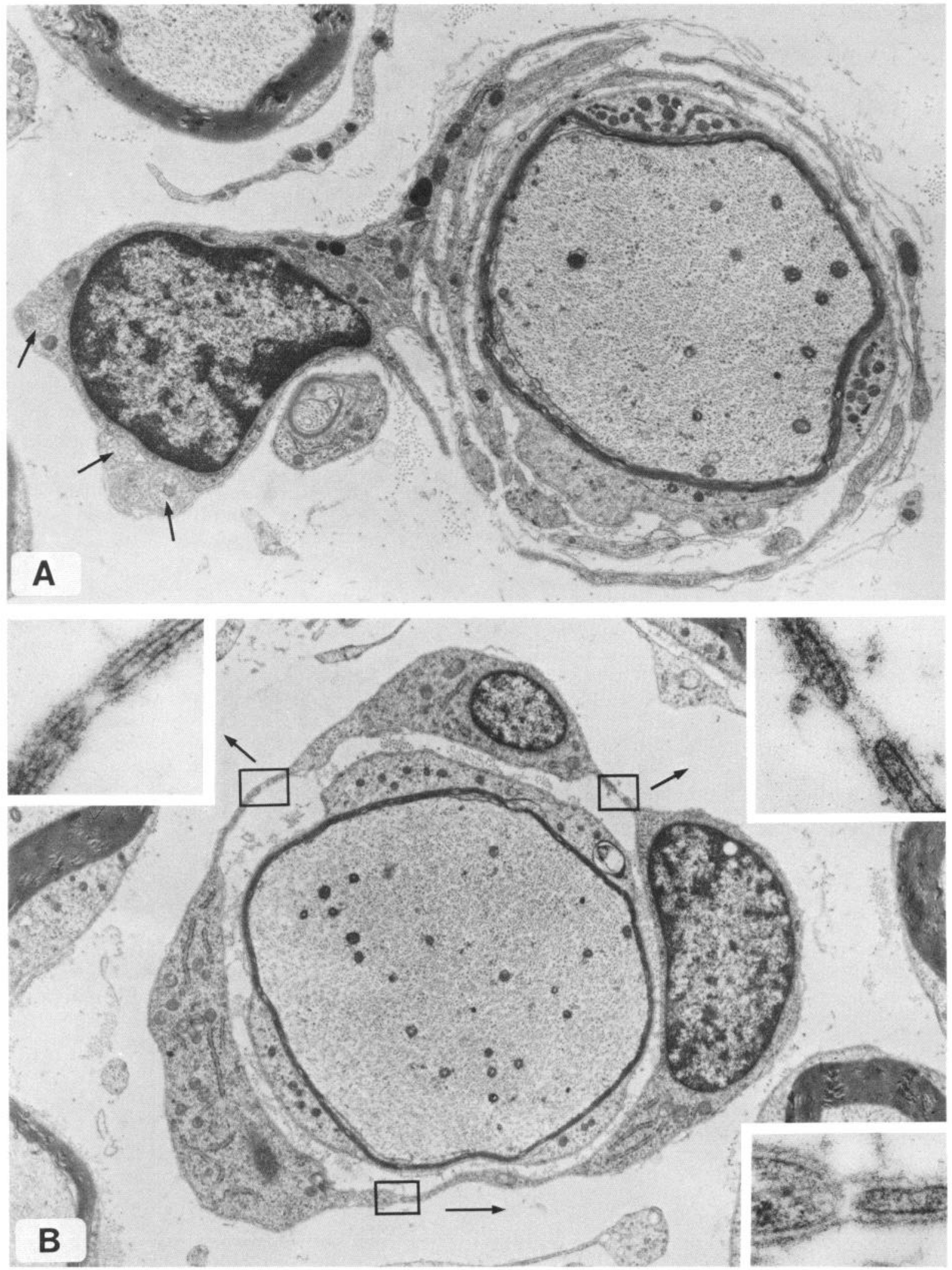

Figure 10. Electron micrographs showing transverse sections through paranodal regions of enlarged nerve fibers $6 \mathrm{~d}$ following IDPN administration. $A(\times 12,800)$, Note that multiple processes from the Schwann cell reach out and surround the paranode, but all remain outside the basal lamina of the nerve fiber. Note also that this Schwann cell contains multiple unmyelinated axons in its perikaryal region (examples identified by arrows). While it is possible that these axons represent collateral sprouts, the paucity of other evidence of sprouting, and numerous examples of similar changes in unmyelinated fibers, suggest that this unmyelinated nerve fiber has been attracted to extend processes toward the demyelinated paranode of a neighboring myelinated fiber. $B(\times 10,500)$, Note that 3 supernumerary Schwann cells form a ring outside the basal lamina of the swollen nerve fiber. The points of apposition of these Schwann cells (boxed regions) are shown in higher power in the insets $(\times 69,000)$. Note that the basal lamina is continuous around this cluster, suggesting that these Schwann cells are products of local proliferation. 
Schwann cells, label was present in the nuclei of some Schwann cells associated with nerve fibers. Most of these were Schwann cells of unmyelinated nerve fibers (Fig. 7), particularly in the dorsal roots, where unmyelinated fibers are numerous. The number of labeled Schwann cells ensheathing axons of unmyelinated fibers was much greater in the swollen regions of roots from the IDPN-treated animals than in control animals.

Of particular interest was the observation that rarc Schwann cells associated with myelinated fibers contained labeled nuclei (Fig. 8). The rarity of this finding is indicated by the fact that only 12 examples were found out of approximately 15,000 nerve fibers present in relevant EM autoradiograms. These labeled Schwann cells were found along internodes of both small and large myelinated fibers (Fig. 8). Although they were restricted to regions of the nerve roots undergoing axonal swelling and paranodal demyelination, the small fibers in these regions experienced little swelling, and the teased fiber studies showed that paranodal demyelination was rare in the small myelinated fibers. These labeled cells were within the basal lamina of the nerve fiber and were shaped by the fiber (Fig. 8), but in all examples identified so far, the labeled perikarya have been separated by 16-20 nm spaces from the external plasmalemma of the myelinated internode; no unequivocal examples of continuity between the plasmalemma of the labeled cell and the mesaxon or the myelin membrane have yet been identified.

The number of supernumerary Schwann cells paralleled the ${ }^{3} \mathrm{H}$-thymidine incorporation in a given region (Fig. 4). Increased numbers of unassociated Schwann cells were never found without abundant evidence of increased ${ }^{3} \mathrm{H}$-thymidine incorporation and mitotic figures indicating local Schwann cell proliferation. As the swellings passed from the regions nearest the nerve cell bodies and ${ }^{3} \mathrm{H}$-thymidine incorporation fell, the number of unassociated cells began to decrease. As discussed below, these data suggest supernumerary Schwann cells die as the nerve fibers return toward normal.

\section{Distribution of supernumerary Schwann cells along nerve fibers}

Teased fiber studies from I14(35)M segments confirmed the absence of Wallerian degeneration and the paucity of segmental demyelination (1 example out of 275 fibers). The major finding was the presence of numerous supernumerary Schwann cells, adherent to the teased nerve fibers, which clustered around the demyelinated paranodal regions (Figs. 9-11). This appearance could readily be seen in longitudinal sections. Supernumerary cells appeared only around demyelinated paranodes and were not seen around fibers that showed no demyelination nor in regions of the nerve roots in which axonal swelling and paranodal demyelination were absent. Mitotic figures and cells incorporating tritiated thymidine were particularly numerous in these paranodal Schwann cell clusters, indicating local proliferation (Fig. 6). In electron micrographs, these clusters of cells often showed multiple cells within a single basal lamina, reflecting this local proliferation (Fig. 10).

Few supernumerary cells were present along the internode (Figs. 9, 12). In longitudinal electron micrographs, such cells, when present, often showed a clear polarity, with the perikaryal region surrounded by basal lamina and the other pole containing an extending region with multiple fine processes but no basal lamina. Schwann cells often extended a process reaching toward a demyelinated paranode from some distance away; usually these were supernumerary Schwann cells, but occasionally
Schwann cells of unmyelinated nerve fibers extended processes to paranodally demyelinated regions of neighboring fibers (Figs. $10,11)$. Both in internodal and paranodal regions the supernumerary Schwann cells were, for the most part, outside the basal lamina of the nerve fiber. Occasionally, Schwann cells penetrated beneath the basal lamina to ensheath the demyelinated paranodes (Figs. $6 C, 11$ ). Very rarely were short remyelinated internodes formed in these regions (2 examples out of 275 teased fibers). More frequently, as axonal calibers returned toward normal, the daughter Schwann cells appeared to be displaced as the myelin sheath of the parent Schwann cells remyelinated the paranodes (Fig. 3).

Phagocytic cells were uncommon in the endoneurial space and the paranodal regions in this study; as previously described, these cells do participate in segmental demyelination at late stages after IDPN administration (Shimono et al., 1978; Griffin and Price, 1981a).

\section{Perikaryal responses}

The perikaryal region of the enlarged nerve fibers showed dramatic changes. These included a marked increase in the volume of the perikaryon, nuclear enlargement with dispersion of the heterochromatin and development of fine euchromatin, increased prominence of the rough endoplasmic reticulum, and hypertrophy of the Golgi apparatus (Fig. 13A).

In addition, changes here termed "girdling" and perikaryal "stalk formation" were frequently seen (Figs. 13, 14). In cross section the perikaryal region became connected to the abaxonal Schwann cell cytoplasm by a constricted region of cytoplasm; this constriction might gently girdle the Schwann cell (Fig. 13B) or produce a very thin stalklike connection (Figs. 13, $C-E ; 14$ ). These stalks often arose from the outer lip of the external mesaxon (Fig. 14A). The stalks were as small as $1 \mu \mathrm{m}$ in diameter, as recognized by serial sections. Longitudinal sections through these stalks indicated that they could extend considerable distances along the fiber (Fig. 15). Perikaryal girdling and stalk formation are not specific to giant axonal neuropathies; we have found examples in experimental lysolecithin-induced demyelination and in a sural nerve biopsy from a patient with acquired demyelinating neuropathy (not shown).

\section{Discussion}

The major changes in Schwann cells observed in this study were paranodal demyelination, perikaryal girdling and stalk formation, Schwann cell proliferation, formation of clusters of Schwann cells over the demyelinated paranodes, and changes in the volumc of myclin in the internodes. The last of these changes will be described separately. All of these changes were associated in space and time with the axonal swellings induced by IDPN, an agent known to impair axonal transport of neurofilaments (Griffin et al., 1978, 1984). We interpret these changes as reflecting a sequence of axonal swelling and consequent paranodal demyelination, resulting in mitosis of neighboring Schwann cells. The daughter Schwann cells formed in this fashion migrate along the swollen nerve fibers to the demyelinated paranodes, where local proliferation contributes to cluster formation.

\section{Sequence of axonal swelling}

The explosive onset of the axonal swellings in the present study probably reflects the relatively rapid rate of slow axonal transport in young rats (Hoffman et al., 1983) and the resulting potential for rapidly evolving neurofilament accumulations when 

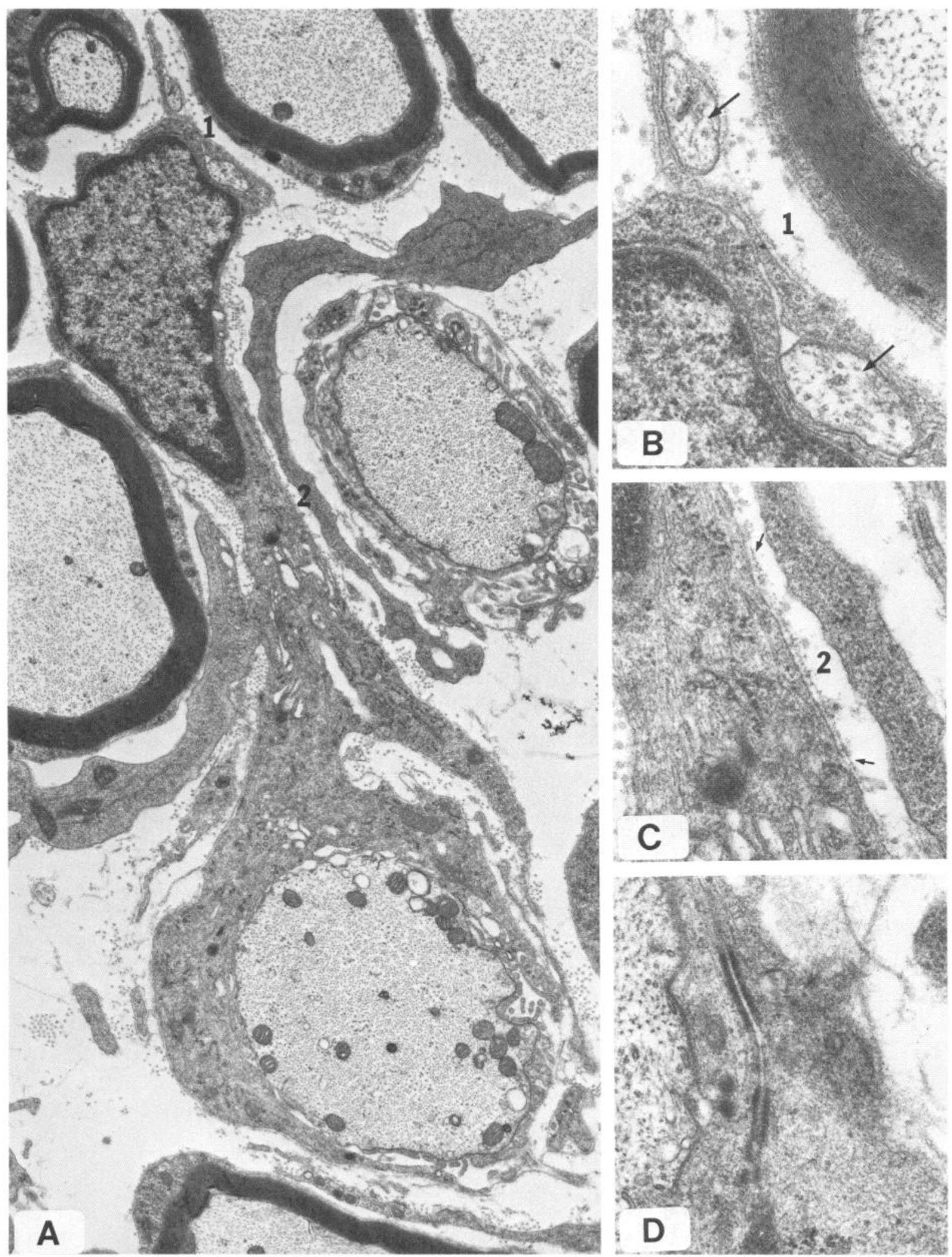

Figure 11. A, Example of a Schwann cell extending a long process to surround and partially ensheath the nodal region of a swollen nerve fiber in an I8(29) rat. $\times 11,800$. Note that unmyelinated axons (arrows) are present near the perikaryon of this Schwann cell (region 1 , seen in $B$ ). That this cell is a Schwann cell is indicated by the basal lamina (arrows) surrounding the entire perikaryal region and most of the extending process (see region 2, shown at higher magnification in $C$ ). In addition, as shown in $D$ (from a different section through this same nerve fiber), desmosome-like junctions are present at the interface between this Schwann cell and the internodal Schwann cell. Taken together, these features suggest that this figure illustrates the Schwann cell of an unmyelinated nerve fiber that has been recruited to ensheath the demyelinated segment of a myelinated nerve fiber some distance away. $B-D: \times 40,500$. 

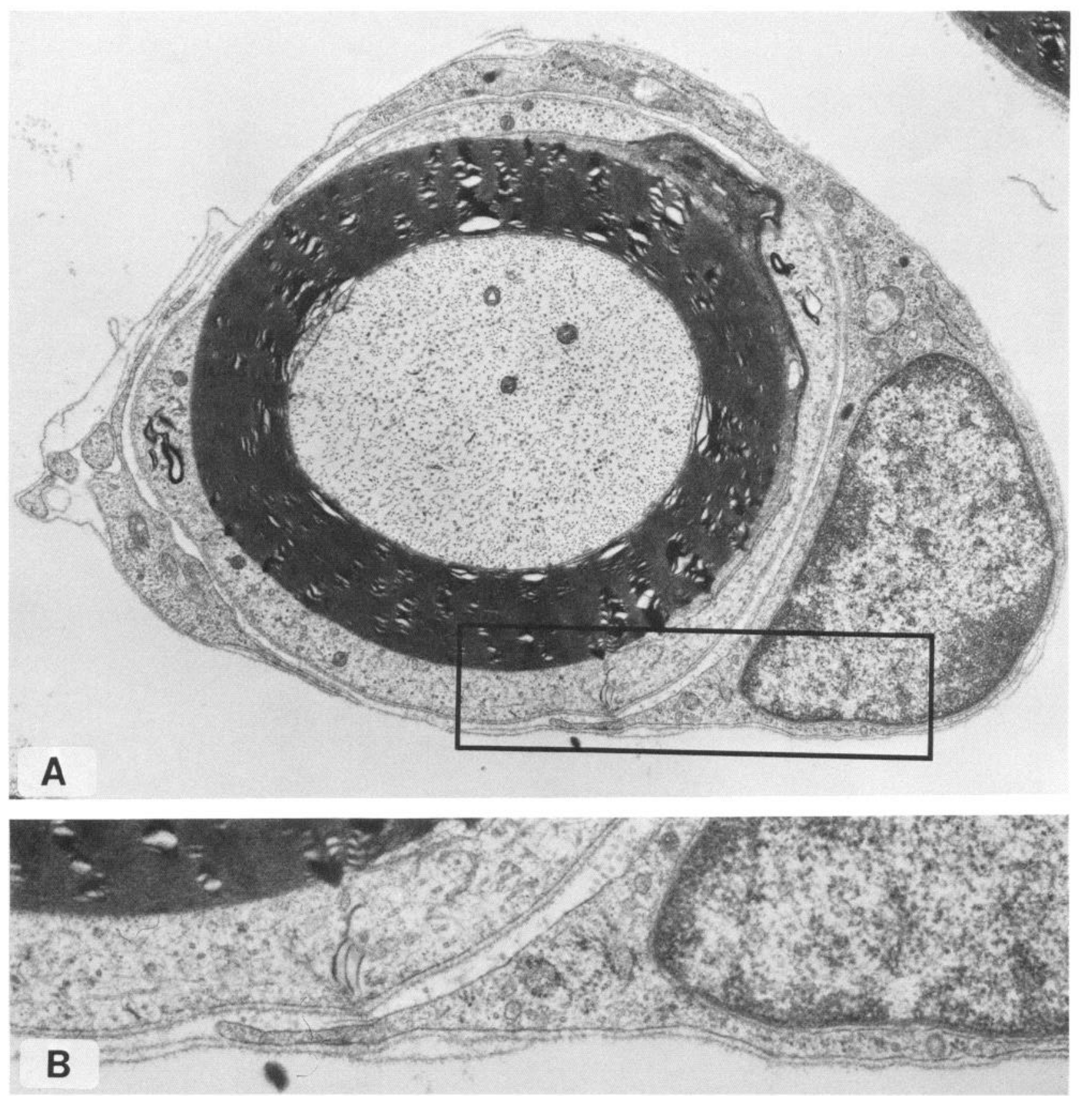

Figure 12. A, Transverse section of a supernumerary Schwann cell encircling an internode in the proximal ventral root of an $\mathrm{I} 6(27)$ rat. $\times 16,000$. The boxed region is shown at higher magnification in $B(\times 37,000)$. Note that the myelinated fiber has an intact basal lamina; the encircling cell has a basal lamina on its external surface but an interrupted basal lamina on its inner surface.

transport is impaired (Griffin et al., 1984). Similarly, the rapid return of the axonal swellings toward normal calibers may reflect reversal of the transport block and restoration of more normal neurofilament transport. The decrease of axonal swelling in proximal regions of the nerve by $14 \mathrm{~d}$ was the result of the proximal-to-distal migration of the neurofilamentous masses (Cavanagh, 1982) at rates approaching $1 \mathrm{~mm} / \mathrm{d}$. This migration of the axonal swellings recalls the original observations of axonal transport made by Weiss and Hiscoe (1948), who found that "dammed" axoplasm, when released, moved centrifugally down the nerve at $1 \mathrm{~mm} / \mathrm{d}$. Interestingly, this seminal study has rarely been reproduced; the present data indicate that, after temporary pharmacologic blockade of neurofilament transport, phenom- ena very similar to those described by Weiss and Hiscoe can be achieved.

\section{Paranodal demyelination}

Paranodal demyelination in giant axonal neuropathies has been extensively studied. These changes are associated with slowing of impulse conduction and, in a smaller proportion of fibers, with conduction block (Gold and Lowndes, 1984; Stanley et al., 1985). In affected fibers the nodal staining pattern produced by ferric ion-ferricyanide techniques can be distorted or redistributed (Jones and Cavanagh, 1983b). The paranodal changes in the IDPN model are generally similar to those described in other neurofilamentous neuropathies (Spencer and Schaumburg, 1977; 

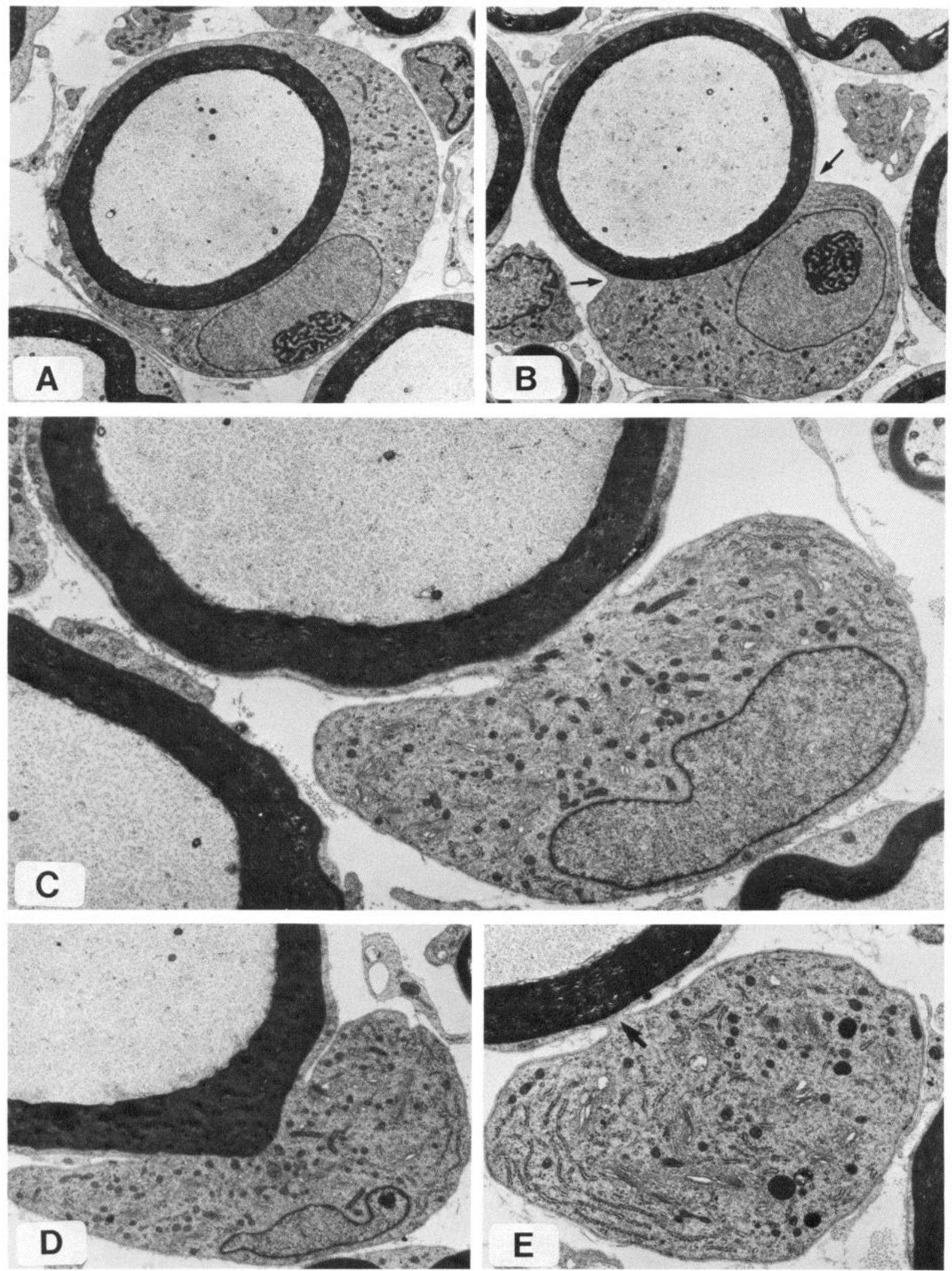

Figure 13. Electron micrographs of transverse sections through the perikaryal region of motor nerve fibers at early stages after IDPN intoxication. These micrographs illustrate nuclear changes, perikaryal "girdling," and stalk formation. In $A(\times 4500)$, note that the axon is enlarged and densely packed with neurofilaments; the myelin sheath is relatively thin because of the increase in axonal diameter, but its absolute thickness is maintained. The nucleus is euchromatic and the nucleolus is enlarged. The Schwann cell cytoplasm contains abundant Golgi. In $B(\times 4100)$, similar nuclear changes are found in a fiber with mild perikaryal "girdling"; the site of constriction is identified by arrows. $C(\times 9300)$ and $D(\times 6900)$ illustrate more severe examples of perikaryal girdling, and in $E(\times 9300)$, the perikaryal region is connected to the abaxonal Schwann cell cytoplasm by an attenuated connection (arrow). Note again abundant Golgi in the perikaryal region. 

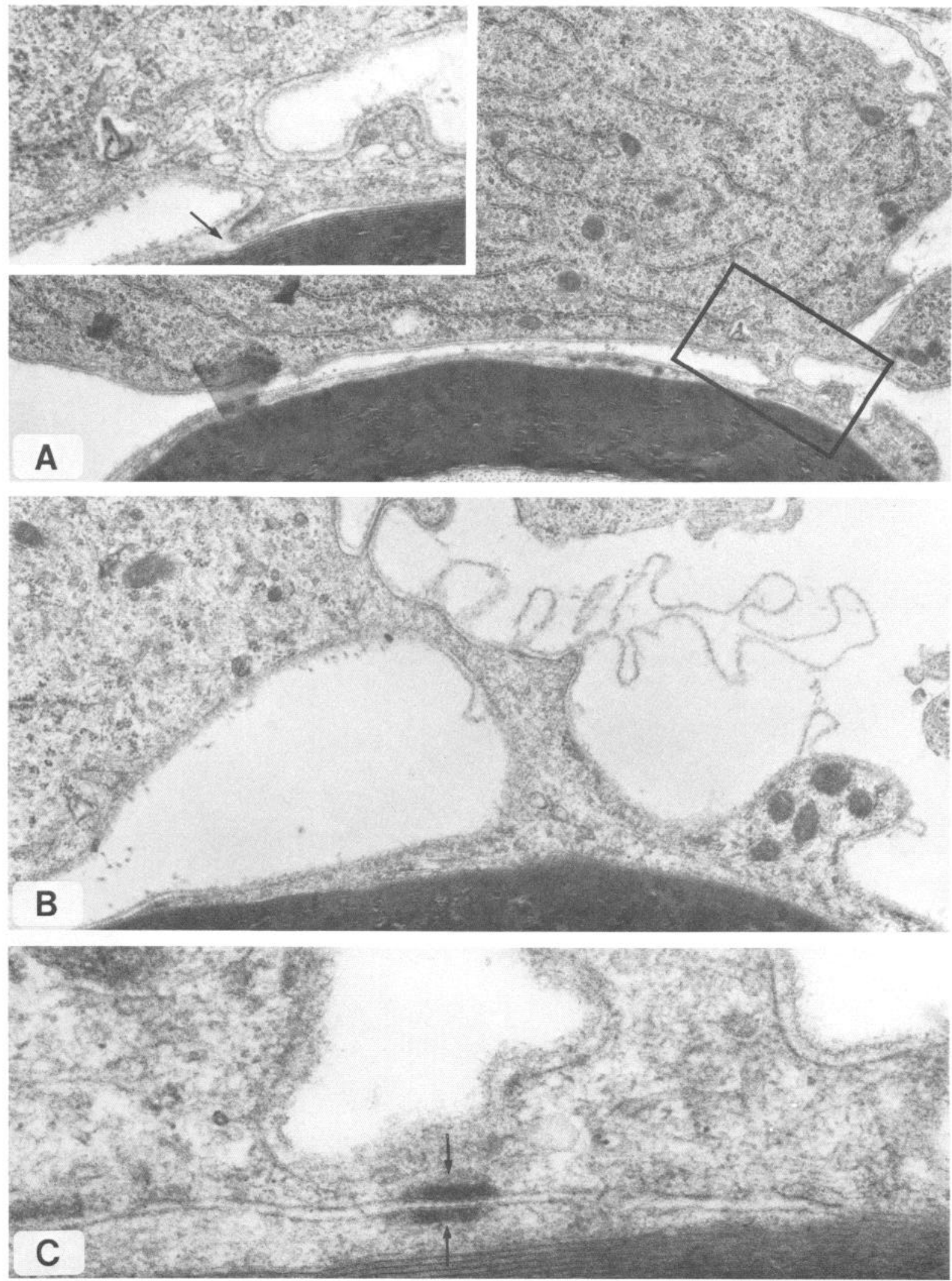

Figure 14. Electron micrographs of transverse sections of enlarged nerve fibers from the ventral roots of IDPN-treated animals, showing at higher magnification perikaryal stalk formation. In $A(\times 18,000)$, the large perikaryal region is connected to the abaxonal Schwann cell cytoplasm by a markedly attenuated stalk (boxed region). Note in the inset $(\times 44,000)$ that this stalk arises from the outer lip of the external mesaxon (arrow). In $B(\times 26,000)$, the continuity of Schwann cell cytoplasm through the stalk is apparent; note that a loosened serpentine basal lamina is present around this stalk, in contrast to the smooth, tightly adherent basal lamina in $A . C(\times 90,000)$ shows an example of desmosomal junction formation (arrows) in the elongated outer mesaxon of a fiber undergoing perikaryal stalk formation. The stalk is out of the field illustrated, to the left and above. 

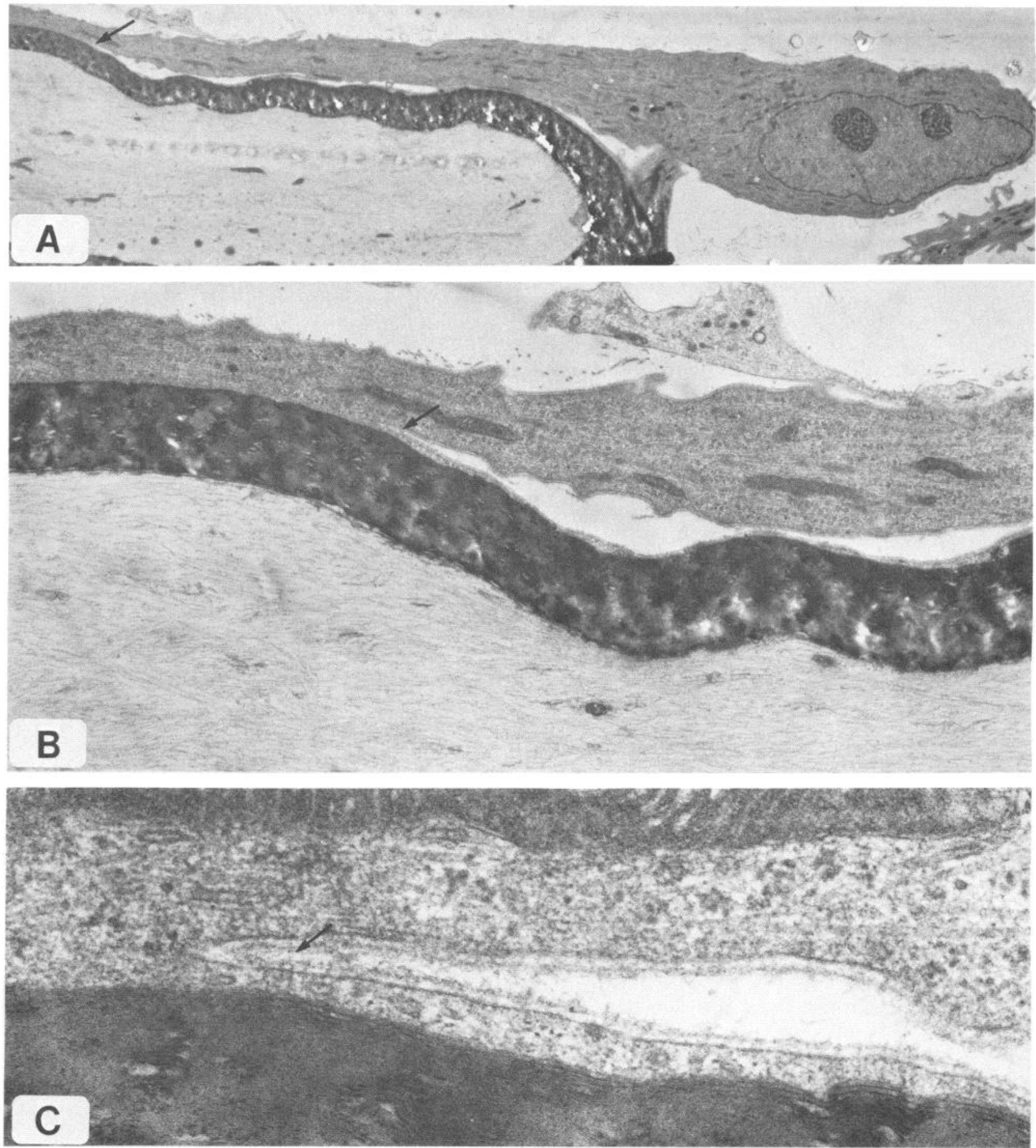

Figure 15. A single nerve fiber shown at increasing magnifications, illustrating stalk formation in a longitudinal section. In $A(\times 3000)$, this obliquely sectioned fiber shows an attenuated connection between the perikaryal region and abaxonal Schwann cell cytoplasm $($ arrow). In $B(\times 12,400)$, this connection is seen at higher magnification (arrow). In $C(\times 77,000)$, the continuity of Schwann cell cytoplasm between the stalk and the abaxonal region is apparent, as is the smooth reflection of the basal lamina in the acute angle formed by this stalk (arrow). Stalk formation of this type may make identification of the attachments between perikarya and myelinated nerve fibers difficult.

Jones and Cavanagh, 1983a). However, the rapidly evolving swellings in this model have no predilection for the proximal paranode; rather, the node, paranode, and internode are all enlarged in a fusiform fashion (Fig. 2). We interpret this early paranodal demyelination as representing a passive displacement of myelin terminal loops due to enlargement of the underlying axon; there is no morphologic evidence of myelin degradation.
As axonal calibers return to normal the outermost terminal loops return to the regions of their original attachment sites (Fig. $3)$.

\section{Schwann cell division}

The axonal swelling and paranodal demyelination were associated with abundant Schwann cell proliferation. The stimulus 
for Schwann cell division is likely to result from the paranodal demyelination. Because in the present material the distribution of paranodal demyelination closely paralleled that of the axonal swellings, measurements of axonal caliber provide a convenient index to the extent of demyelination. We found that the proliferation of Schwann cells parallcled the distribution of axonal swellings along the nerve root. As the swellings passed out of a given region, proliferation was reduced and the number of supernumerary Schwann cells diminished. This decrease in the number of supernumerary Schwann cells probably reflected death and disappearance of Schwann cells that were unable to establish sustained contact with an axon. Conceivably, some portion of these Schwann cells might have migrated down the root as the wave of axonal swelling advanced, but this explanation need not be invoked; the extent of Schwann cell proliferation, as judged by ${ }^{3} \mathrm{H}$-thymidine incorporation, appears adequate to account for the numbers of supernumerary Schwann cells appearing in distal regions of nerve roots as axonal swellings appeared.

\section{Schwann cell migration and paranodal Schwann cell clusters}

New Schwann cells clustered around the demyelinated paranodes (Figs. 6, 9, 10). Most of these supernumerary Schwann cells were outside the basal lamina of the nerve fibers around which they clustered, and relatively few penetrated the basal lamina and contacted the axolemma. The fibers illustrated were fixed before teasing, but such clusters were seen in unfixed teased nerve fibers, suggesting that the supernumerary Schwann cells must be adherent to the nerve fibers in some fashion, perhaps to the basal lamina.

Mitotic figures were frequent within these paranodal clusters, occasionally forming a ring of contiguous Schwann cells, sharing a continuous basal lamina. Taken together these observations strongly suggest that the supernumerary Schwann cells, produced by initial Schwann cell division elsewhere (see below), migrated in the endoneurial space (outside the basal lamina) along the internodes to reach the demyelinated paranodes. Many of the internodal supernumerary Schwann cells exhibited a polarity, with one region extending fine processes, similar to those shown in Figures 10 and 11.

\section{Perikaryal changes}

The most intriguing perikaryal changes were girdling and stalk formation. These changes may be related to those described in 2,5-hcxanedione and alloxan diabetic neuropathies (Powcll ct al., 1977; Powell and Myers, 1984). We have observed perikaryal girdling in other demyelinating neuropathies, but it tends to be obscured by simultaneous demyelination or fiber degeneration and the related cellular changes. In the present material the perikaryal responses stand out because of the synchronous evolution of Schwann cell responses and the preservation of the internodal myelin. The longest and thinnest perinuclear stalks suggest a perikaryal-myelin relationship more like that seen in oligodendrocytes, rather than in normal Schwann cells.

\section{Speculative reconstruction of Schwann cell responses during paranodal demyelination}

Each of the various aspects of Schwann cell behavior described above, taken in isolation, is capable of a variety of interpretations, as indicated. In this reconstruction we suggest that these changes may represent an interrelated sequence.

1. Paranodal demyelination provides a mitogenic signal for
Schwann cells. Possible signals could include loss of contact inhibition between adjacent Schwann cells, exposure of the paranodal and/or internodal axolemma, or release of diffusible mitogens. Membrane-bound axolemmal factors are known to induce mitosis of cultured Schwann cells (Salzer et al., 1980; DeVries et al., 1982). However, in the present material much of the Schwann cell division occurs in neighboring unmyelinated nerve fibers, in small myelinated fibers that do not themselves undergo paranodal demyelination, and in supernumerary Schwann cells located in the endoneurial space outside the basal lamina, remote from direct contact with demyelinated axolemma. For these reasons we speculate than an important mitogenic signal may be a soluble factor that diffuses into the endoneurial fluid, thereby accounting for division of these several types of Schwann cells in the surrounding region.

2. During the phase of Schwann cell division, the myelin sheaths of large fibers are simultaneously undergoing rapid sheath expansion, involving dramatic increases in the total myelin volume in the internode, as described elsewhere. Some of the perikaryal changes (hypertrophy of the nucleolus and Golgi apparatus) probably reflect amplified synthesis of myelin constituents. Others, such as stalk formation, might be involved in proliferation. As indicated below, the results raise the possibility that Schwann cells might divide while maintaining a myelin sheath. If so, stalk formation might provide a mechanism for asymmetric mitosis, in which 1 cell is pinched off the stalk to lie in the endoneurial space, while the nucleus of the other might return to the normal perikaryal position with stalk retraction.

3. We speculate that a chemotropic factor, either the mitogenic signal or another, is capable of attracting Schwann cells over at least short distances (a few hundred microns) to regions of demyelination. Such migration may be haptotactic along the outside of the basal lamina of affected nerve fibers, to which the migrating free Schwann cells appear adherent. Local proliferation continues in the resulting paranodal Schwann cell clusters.

4. Some Schwann cells in the paranodal clusters penetrate the basal lamina of the demyelinated regions, perhaps by proteases such as plasminogen activator. In most models of demyelination such successful Schwann cells will ensheath a demyelinated axonal segment and establish short myelinated internodes. In the present model, concomitant with the decrease in axonal caliber (beginning 10-14 d after swelling), the outer lamellae of the original myelin sheath returns to the original attachment sites. The original internodes thereby displace the daughter Schwann cells (compare Bonnard-Toulze and Raine, 1980) and short internodes are rare.

5. With paranodal remyelination Schwann cell proliferation of neighboring Schwann cells ceases and supernumerary Schwann cells disappear, probably as a result of cell death.

\section{What are the sources of new Schwann cells?}

The source of supernumerary Schwann cells during pure paranodal demyelination is an intriguing issue. Schwann cells are thought not to divide after initial myelination in normal peripheral nerves (Martin and Webster, 1973). In PNS diseases, Schwann cell division is well recognized, but in most pathological material one or more obvious sources of new Schwann cells can be identified. Such sources of new Schwann cells include those Schwann cells that have lost their myelin sheaths as a result of segmental demyelination (Hall and Gregson, 1974) or Wallerian degeneration (Politis et al., 1982). In the present mod- 
el, both Wallerian degeneration and segmental demyelination are rare in the first $30 \mathrm{~d}$, so that the usual sources of dividing Schwann cells are virtually absent. We found that, in nerve segments containing paranodal demyelination of large myelinated fibers, Schwann cells of unmyelinated fibers as well as occasional Schwann cells associated with large and small myelinated fibers are stimulated to incorporate ${ }^{3} \mathrm{H}$-thymidine.

The present results provide the first direct demonstration that Schwann cells associated with myelinated fibers are capable of DNA synthesis, although the possibility that such cells could divide was suggested by Hall (1978) and Raine et al. (1982). It must be emphasized that we have not been able to trace the plasmalemma of a labeled Schwann cell perikaryon into the outer mesaxon and myelin sheath, a finding that would definitively demonstrate that the dividing Schwann cells were simultaneously maintaining myelin sheaths. If division occurred during perikaryal stalk formation, serial transverse sections would be required to identify continuity between the dividing perikaryon and the site of stalk attachment (e.g., Fig. 15). The alternative formulation is that occasional nerve fibers have "uncommitted" Schwann cells within the internodal basal lamina. No previous evidence supports this possibility, but the labcled cells in this position raise the possibility that it could be a rare occurrence in normal nerves.

This latter possibility of uncommitted Schwann cells raises the final question: Are Schwann cells associated with nerve fibers - myelinated and unmyelinated - the sole sources of new supernumerary Schwann cells in this model? In regions near the advancing front of axonal swelling and paranodal demyelination, most of the labeled Schwann cells are in the endoneurial space, outside the basal lamina of neighboring nerve fibers. Based on estimates of an $18 \mathrm{hr}$ generation time for Schwann cells (Asbury, 1967), it is likely that no more than 2 or 3 generations could have been produced from the time of the earliest invasion of the region by axonal enlargement. Thus, we cannot exclude the possibility that a quantitatively important source of new Schwann cells might be a previously unrecognized population of uncommitted or undifferentiated Schwann cells or Schwann cell progenitors within the endoneurial space. Such cells might be included within the group of labeled and mitotic cells that lack basal laminae. Whether such uncommitted "satellite" Schwann cells exist should be established by ongoing studies examining the earliest stages of the Schwann cell response. By utilizing a variety of postlabeling intervals, as well as serial section reconstructions of teased fibers, such studies will determine the quantitative contributions of proliferation of the Schwann cells of unmyelinated fibers, myelinated fibers, the postulated satellite Schwann cells, and continued proliferation of newly formed daughter Schwann cells.

\section{References}

Asbury, A. K. (1967) Schwann cell proliferation in developing mouse sciatic nerve. J. Cell Biol. 34: 735-743.

Asbury, A. K., M. K. Gale, S. C. Cox, J. R. Baringer, and B. O. Berg (1972) Giant axonal neuropathy: A unique case with segmental neurofilamentous masses. Acta Neuropathol. (Berl.) 20: 237-247.

Bonnard-Toulze, E. N., and C. S. Raine (1980) Remodelling during remyelination in the peripheral nervous system. Neuropathol. Appl. Neurobiol. 16: 279-290.

Cavanagh, J. B. (1982) The pattern of recovery of axons in the nervous system of rats following 2,5-hexanediol intoxication: A question of rheology? Neuropathol. Appl. Neurobiol. 8: 19-34.

DeVries, G. H., J. L. Salzer, and R. P. Bunge (1982) Axolemmaenriched fractions isolated from PNS and CNS are mitogenic for cultured Schwann cells. Dev. Brain Res. 3: 295-299.
Friede, R. L., and A. J. Martinez (1970) Analysis of axon-sheath relations during early Wallerian degeneration. Brain Res. 19: 199212.

Gold, B. G., and H. E. Lowndes (1984) Electrophysiological investigation of $\beta, \beta^{\prime}$-iminodipropionitrile neurotoxicity. II. Intracellular recording in spinal cord. Brain Res. 308: 235-244.

Gombault, A. (1880) Contribution a l'etude anatomique de la nervite parenchymateuse subaique et chronique: Nervite segmentaire periaxile. Arch. Neurol. (Paris) 1: 177-190.

Griffin, J. W., and D. L. Price (1981a) Segmental demyelination in experimental IDPN and hexacarbon neuropathies: Evidence for an axonal influence. Lab Invest. 45: 130-141.

Griffin, J. W., and D. L. Price (1981b) Schwann cell and glial responses in $\beta, \beta^{\prime}$-iminodipropionitrile intoxication. I. Schwann cell and oligodendrocyte ingrowths. J. Neurocytol. 10: 995-1007.

Griffin, J. W., P. N. Hoffman, A. W. Clark, P. T. Carroll, and D. L. Price (1978) Slow axonal transport of neurofilament proteins: Impairment by $\beta, \beta^{\prime}$-iminodipropionitrile administration. Science 202 : 633-635.

Griffin, J. W., D. L. Price, D. B. Drachman, and J. Morris (1981) Incorporation of axonally transported glycoproteins into axolemma during nerve regeneration. J. Cell Biol. 88: 205-214.

Griffin, J. W., D. C. Anthony, K. E. Fahnestock, P. N. Hoffman, and D. G. Graham (1984) 3,4-Dimethyl-2,5-hexanedione impairs the axonal transport of neurofilament proteins. J. Neurosci. 4: 15161526.

Hall, S. M. (1978) The Schwann cell: A reappraisal of its role in the peripheral nervous system. Neuropathol. Appl. Neurobiol. 4: 165176.

Hall, S. M., and N. A. Gregson (1974) The effects of mitomycin C on remyelination in the peripheral nervous system. Nature 252: 303305.

Hoffman, P. N., R. J. Lasek, J. W. Griffin, and D. L. Price (1983) Slowing of the axonal transport of neurofilament proteins during development. J. Neurosci. 3: 1694-1700.

Hoffman, P. N., J. W. Griffin, and D. L. Price (1984) Control of axonal caliber by neurofilament transport. J. Cell Biol. 99: 705-714.

Hoffman, P. N., G. Thompson, J. W. Griffin, and D. L. Price (1985) Changes in axonal caliber during nerve regeneration: Evidence for anterograde transport of the cytoskeleton. J. Cell Biol. 101: 133-134.

Jones, H. B., and J. B. Cavanagh (1983a) Cytochemical staining characteristics of peripheral nodes of Ranvier in hexacarbon intoxication. J. Neurocytol. 12: 459-473.

Jones, H. B., and J. B. Cavanagh (1983b) Distortions of the nodes of Ranvier from axonal distention by filamentous masses in hexacarbon intoxication. J. Neurocytol. 12: 439-458.

Martin, J. R., and H. deF. Webster (1973) Mitotic Schwann cells in developing nerve: Changes in shape, fine structure, and axon relationship. Dev. Biol. 32: 417-431.

Politis, M. J., N. Sternberger, K. Ederle, and P. S. Spencer (1982) Studies on the control of myelinogenesis. IV. Neuronal induction of Schwann cell myelin-specific protein synthesis during nerve fiber regeneration. J. Neurosci. 2: 1252-1266.

Powell, H. C., and R. R. Myers (1984) Axonopathy and microangiopathy in chronic Alloxan diabetes. Acta Neuropathol. 65: 128-137.

Powell, H. C., T. Koch, R. Garrett, and P. W. Lampert (1978) Schwann cell abnormalities in 2,5-hexanedione neuropathy. J. Neurocytol. 7: 517-528.

Raine, C. S., A. M. Brown, and D. E. McFarlin (1982) Heterotopic regeneration of peripheral nerve fibers into the subarachnoid space. J. Neurocytol. 11: 109-118.

Salzer, J. L., R. P. Bunge, and L. Glaser (1980) Studies of Schwann cell proliferation. III. Evidence for the surface localization of the neurite mitogen. J. Cell Biol. 84: 767-778.

Shimono, M., K. Izumi, and Y. Kuroiwa (1978) 3,3'-Iminodipropionitrile induced centrifugal segmental demyelination and onion bulb formation. J. Neuropathol. Exp. Neurol. 37: 375-386.

Spencer, P. S., and H. H. Schaumburg (1977) Ultrastructural studies of the dying back process. III. The evolution of experimental peripheral giant axonal degeneration. J. Neuropathol. Exp. Neurol. 36: 276299.

Stanley, E., J. W. Griffin, and K. E. Fahnestock (1985) Effects of IDPN-induced axonal swellings and paranodal demyelination on conduction in motor nerve fibers. J. Neurol. Sci. 69: 183-200.

Weiss, P., and H. B. Hiscoe (1948) Experiments on the mechanism of nerve growth. J. Exp. Zool. 107: 315-395. 